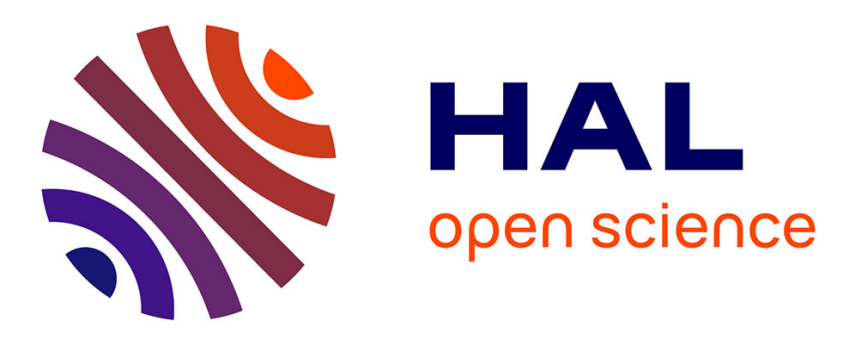

\title{
Disentangling Cro-Magnon: The dental and alveolar remains
}

Erik Trinkaus, Sarah A Lacy, Adrien Thibeault, Sébastien Villotte

\section{To cite this version:}

Erik Trinkaus, Sarah A Lacy, Adrien Thibeault, Sébastien Villotte. Disentangling Cro-Magnon: The dental and alveolar remains. Journal of Archaeological Science: Reports, 2021, 37, 10.1016/j.jasrep.2021.102911 . hal-03441696

\section{HAL Id: hal-03441696 \\ https://hal.science/hal-03441696}

Submitted on 22 Nov 2021

HAL is a multi-disciplinary open access archive for the deposit and dissemination of scientific research documents, whether they are published or not. The documents may come from teaching and research institutions in France or abroad, or from public or private research centers.
L'archive ouverte pluridisciplinaire HAL, est destinée au dépôt et à la diffusion de documents scientifiques de niveau recherche, publiés ou non, émanant des établissements d'enseignement et de recherche français ou étrangers, des laboratoires publics ou privés. 


\section{Disentangling Cro-Magnon: The Dental and Alveolar Remains}

3 Erik Trinkaus, ${ }^{\text {a,b,* }}$ Sarah A. Lacy, ${ }^{c}$ Adrien Thibeault ${ }^{d}$ and Sébastien Villotte ${ }^{d}$

a Department of Anthropology, Washington University, Saint Louis, MO 63130, USA; trinkaus@wustl.edu

7 b 32 Cliff Street, Burlington VT 05401, USA

${ }^{\mathrm{c}}$ Department of Anthropology, California State University Dominguez Hills, Carson, CA 90747,

$9 \quad$ USA; slacy@scudh.edu

10 d Université de Bordeaux, CNRS, PACEA, UMR 5199, F-33615 Pessac, France;

11 adrien.thibeault@u-bordeaux.fr; sebastien.villotte@u-bordeaux.fr

$12 *$ Corresponding author

15 The authors declare no conflicts of interest.

\section{Author contributions:}

18 Erik Trinkaus: Conceptualization, Data curation, Investigation, Methodology, Visualization, 19 Writing - original draft. Sarah A. Lacy: Funding acquisition, Data curation, Investigation,

20 Methodology, Writing-review \& editing. Adrien Thibeault: Methodology, Visualization,

21 Writing-review \& editing. Sébastien Villotte: Conceptualization, Funding acquisition,

22 Investigation, Project administration, Resources, Writing-review \& editing.

Corresponding author: Erik Trinkaus trinkaus@wustl.edu 
Highlights

The Cro-Magnon human remains include the dentoalveolar remains of four individuals Cro-Magnon 1 (4253) exhibits advanced periodontal resorption and 3 granulomata Cro-Magnon 4257/58 has exceptionally large molars, for an Upper Paleolithic human ․ Cro-Magnon 4253, 4256 and 4257 exhibit rotated premolars $\square$ Cro-Magnon teeth and alveoli are otherwise unexceptional for the Upper Paleolithic

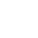

\section{Abstract}

The dental and alveolar remains of the Upper Paleolithic early modern humans from the Abri de Cro-Magnon (Dordogne, France) are described and reassessed, building on descriptions since their discovery in 1868. There are four individuals represented; two (Cro-Magnon (CM) 4253 and 4254) are portions of numbered skulls (Cro-Magnon 1 and 2) and two (Cro-Magnon 4256 and 4257/58) are unassociated but likely deriving from Cro-Magnon 3 and 4. CM 4253 exhibits advanced periodontal lesions, likely secondary to tooth wear, CM 4256 has moderate alveolar resorption, but the others show little alveolar pathology. CM 4253, 4256 and 4257 have premolar rotation, and CM 4257/58 had impacted M3s. The CM 4254 molars are average in size for the Late Pleistocene, but those of CM 4257/58 are at or beyond the upper limits of known ranges of Upper Paleolithic variation. Only the dental dimensions of the CM 4257/58 molars are exceptional for earlier Upper Paleolithic humans.

Key Words: Paleoanthropology, Upper Paleolithic, Gravettian, Dentition, Paleopathology, Granulomata, Caries

\section{Introduction}

The Cro-Magnon rock shelter (Les Eyzies-de-Tayac-Sireuil, Dordogne, France) is one of the premier Upper Paleolithic sites, best known for establishing the contemporaneity of early modern humans with Upper Paleolithic assemblages and Pleistocene fauna (Broca, 1868; Lartet, 1868). Although described in relative detail by Broca (1868) and Pruner-Bey (1865-75) shortly after their discovery, and reassessed 100 years later by Vallois and Billy (1965), the human skeletal assemblage from Cro-Magnon has remained poorly known despite the incorporation of various elements into Late Pleistocene comparative analyses. In this context, and in the 
61 framework of a broader refocus on western Eurasian Upper Paleolithic human paleobiology, we 62 have undertaken the reassessment of the Cro-Magnon human remains (Thibeault and Villotte, 63 2018; Villotte and Balzeau, 2018; Partiot et al., 2020; Villotte et al., 2020); in this contribution, 64 we provide a description and reassessment of the dental and alveolar remains of the adults.

The human remains from Cro-Magnon were formerly attributed generally to the "Aurignacian," but they are currently dated to the Mid Upper Paleolithic (MUP), to an early phase of the Gravettian technocomplex (33-31,000 cal BP) based on radiocarbon dating of associated archeological remains (Henry-Gambier, 2002; Henry-Gambier et al., 2013). The relatively abundant human remains represent all portions of the skeleton. However, they became commingled, whether in situ or subsequently, resulting in various attempts to reassociate them by individual (e.g., Broca, 1868; Pruner-Bey, 1865-75; Vallois and Billy, 1965; Henry-Gambier et al., 2013; Thibeault and Villotte, 2018; Villotte and Balzeau, 2018; Villotte et al., 2020). Based on the cranial remains, four adults are present (Broca, 1868; Lartet, 1868; Pruner-Bey, 1965-75; Vallois and Billy, 1965). Gambier et al. (2006) also identified four adults from pelvic remains, but reassessment indicates that only three are pelvically represented (Thibeault and Villotte, 2018; see also Pruner-Bey, 1865-75). Most recently, Villotte et al. (2020) determined that there is a fourth adult represented by the ulnae.

In this contribution to the reassessment of the Cro-Magnon assemblage, we focus on the adult dental and alveolar remains. These remains were a primary focus of the original CroMagnon description by Broca (1868), in that he used the dental remains to assess the ages-atdeath of three individuals. He assessed the associated maxillae and mandible of Cro-Magnon 1 and the maxillae of Cro-Magnon 2, plus the isolated maxilla (Cro-Magnon (CM) 4257) which he assigned to Cro-Magnon 3 (Table 1). He did not consider the two separate mandibles, CM 4256 and 4258. These remains were described in more detail with respect to age-at-death, morphology, pathology and dental attrition by Pruner-Bey (1865-75), who assigned them to the four cranially identified individuals. A century later, Vallois and Billy (1965) reassessed the sample with a more inclusive discussion of the full dental and alveolar sample; they attributed the isolated CM 4256 mandible to Cro-Magnon 3, but did not assign the isolated CM 4257 and 4258 elements.

None of these papers provided detailed descriptions of the dental and especially alveolar remains, although Broca (1868) commented in particular on patterns of dental wear and both 
92 Pruner-Bey (1865-75) and Vallois and Billy (1965) provided broader assessments of

93 morphological and paleopathological aspects. The considerations here are intended to both

94 reassess previously noted aspects of these alveolar and dental remains and fill out the

95 descriptions of them.

97 Table 1. Previous assignments of the Cro-Magnon craniomandibular remains with dentoalveolar 98 portions by individual.

\begin{tabular}{llll}
\hline & Broca 1868 & Pruner-Bey 1865-75 & Vallois \& Billy 1965 \\
\hline CM 4253 cranium & Cro-Magnon 1 & Cro-Magnon 1 & Cro-Magnon 1 \\
CM 4253 mandible & Cro-Magnon 1 & Cro-Magnon 1 & Cro-Magnon 1 \\
CM 4254 cranium & Cro-Magnon 2 & Cro-Magnon 2 (“3”) $)^{1}$ & Cro-Magnon 2 \\
CM 4256 mandible & no mention & Cro-Magnon 3 (“2”) & Cro-Magnon 3 \\
CM 4257 maxilla & Cro-Magnon 3 & Cro-Magnon 4 & unassigned \\
CM 4258 mandible & no mention & Cro-Magnon 4 & unassigned
\end{tabular}

99

100

101

102

103

104

105

106

107

108

109

110

111

112

113

114

115

116

${ }^{1}$ Pruner-Bey (1865-75) referred to Cro-Magnon 2 (CM 4254) as number 3, and Cro-Magnon 3 (CM 4255) as number 2.

\section{Materials}

\subsection{The Cro-Magnon Dentoalveolar Remains}

The human remains from the Abri de Cro-Magnon are curated in the Musée de l'Homme, Muséum national d'Histoire naturelle (MNHN), Paris. The specimens of consideration here consist of the maxillae of two crania (CM 4253 [Cro-Magnon 1]) and (CM 4254 (Cro-Magnon 2)), the mandible with the first cranium (CM 4253), an isolated partial maxilla (CM 4257), and two isolated partial mandibles (CM 4256 and 4258).

The Cro-Magnon 4253 maxillae and mandible (Fig. 1) retain their full dental arcades (each M3 to M3), although both have sustained extensive postmortem abrasion and the maxillae in particular retain a coating of irregular carbonate. The carbonate cannot be removed from the fragile bone, and attempts to "clean" the cranium virtually have failed given the thinness of the layer and similar radiodensity to the underlying bone (Fig. S1). Only one partial tooth, the right $\mathrm{M}^{2}$, and partial roots of two others, the right $\mathrm{M}_{1}$ and $\mathrm{M}_{3}$, remain in situ (Fig. 1).

The Cro-Magnon 4254 maxillary alveoli are largely present from the mesial right $\mathrm{M}^{3}$ alveolus to the mesiodistal middle of the left $\mathrm{M}^{1}$ alveolus (Fig. 2). There is erosion especially to 
117 the labial anterior alveoli and the buccal postcanine alveoli. The right $\mathrm{M}^{1}$ and $\mathrm{M}^{2}$ are in situ, and 118 a root fragment of the left $\mathrm{M}^{1}$ is present.

119 Cro-Magnon 4256 (Fig. 3) is a complete mandibular corpus, from incomplete $\mathrm{M}_{3}$

120 alveolus to incomplete $\mathrm{M}_{3}$ alveolus. It is largely without teeth, but the alveolar processes

121 sustained only minor damage, primarily to those of the buccal $\mathrm{M}_{1} \mathrm{~s}$. Although all dental crowns

122 are absent, root portions remains for the left $\mathrm{I}_{1}$ and both $\mathrm{P}_{3}$ s.

123 The Cro-Magnon 4257 left maxilla (Fig. 4) retains the lingual alveoli from the $\mathrm{I}^{1}$ to distal

124 of the $\mathrm{M}^{2}$. There are three teeth remaining, a $\mathrm{P}^{4}$ and the left $\mathrm{M}^{1}$ and $\mathrm{M}^{2}$. The two molars are

125 securely in situ. However, the $\mathrm{P}^{4}$ does not fit the left maxilla (see SI S5). It would be appropriate

126 as a right $\mathrm{P}^{4}$ for the same individual, and it is so considered here.

127 The Cro-Magnon 4258 right posterior mandibular corpus and ramus (Fig. 4) retains the

128 damaged $\mathrm{M}_{1}$ and $\mathrm{M}_{2}$ and the complete $\mathrm{M}_{3}$, the last impacted in its crypt. The buccal alveoli from

129 the mid- $M_{1}$ to the ramus are intact, but there is damage to the lingual $M_{1}$ alveolus and the lingual

$130 \mathrm{M}_{2}$ alveolus was lost. Most of the alveolar margins of the $\mathrm{M}_{3}$ crypt are intact.

\subsection{Comparative Samples}

133 The principal comparative sample, and the primary context for the Cro-Magnon sample,

134 is the human remains from the earlier Upper Paleolithic of Europe, the Early (EUP) and Mid

135 (MUP) Upper Paleolithic combined and referred to as E/MUP. The majority of these remains

136 derive from the MUP. Additional data for dental crown diameters are provided for European

137 Late Upper Paleolithic (LUP) humans, and reference as appropriate is made to Middle

138 Paleolithic late archaic (Neandertal) and early modern human remains.

\section{Methods}

The reassessment of these oral remains is based on visual observation of the original

142 remains in the Musée de l'Homme in 2012 (SAL) and 2018 (ET and SV), combined with images

143 taken in 1978 and 1985. Microtomodensitometric $(\mu \mathrm{CT})$ data for these bones were acquired at

144 the AST-RX platform in the MNHN. They were obtained with the microfocus tube of the $\mu \mathrm{CT}$

145 scanner "v|tome|xL 240" (GE Sensing and Inspection Technologies Phoenix X ray). Each final

146 volume was then reconstructed with isotropic voxels ranging from 30 to $115 \mu \mathrm{m}$ (Table S4) and 
using NRecon v2.0 (Bruker microCT) in 16-bit format. Surface rendering (STL format) of these 3D models was obtained with Avizo v.9 (Visualization Sciences Group Inc.).

Osteometrics are limited to standard dental crown diameters (Bräuer, 1988), discrete occlusal traits follow the ASUDAS system (Turner et al., 1991; Scott and Turner, 1997), and occlusal wear is scored following Smith (1984). Comparative dental crown diameters are provided [as mean \pm standard deviation $(\mathrm{N})$ ]. Mesiodistal diameters of the crowns with interproximal wear were estimated by continuing the rounded crown contour in occlusal view,

154 following Wood and Abbott (1983). Data are from the published literature and personal measurement, and available on request. Right and left diameters, if available for an individual, were averaged prior to graphing and statistical calculations.

\section{Results and Comparisons}

\subsection{Morphology and Dental Dimensions}

The postmortem loss of most of the Cro-Magnon 4253, 4254 and 4256 teeth for which alveoli are preserved, crown breakage to their few remaining teeth, and extensive occlusal wear to the Cro-Magnon 4257 and 4258 molars have resulted in little available morphological data on their dentitions.

As noted by Pruner-Bey (1865-75) and Vallois and Billy (1965), both CM 4254 and 4257 have two rooted $\mathrm{P}^{3}$ s, bilaterally where preserved in the former (Figs. 2 and 4). CM 4253 appears to have had single rooted $\mathrm{P}^{3} \mathrm{~s}$ (Fig. S1). With the possible exception of the CM $4256 \mathrm{M}_{2} \mathrm{~S}$ (Fig. 3),

167 all of the molars or the molar alveoli exhibit clearly separated molar roots, indicating a general absence of taurodontism. Among the maxillary molars, the CM 4254 and $4257 \mathrm{M}^{1} \mathrm{~s}$ appear to

169 have been 4-cusped, or have had well developed hypocones (ASUDAS stage $\approx 4$ ) (Figs. 2 and 4).

170 The CM $4257 \mathrm{M}^{2}$ appears to have had some hypocone reduction (Fig. 4), probably ASUDAS

171 stage 3. None of these molars retain sufficient occlusal morphology for further scoring given 172 wear.

173 The one tooth providing a complete, if partially observable, occlusal surface is the CM

1744258 impacted $\mathrm{M}_{3}$. The tooth has a simple $\mathrm{Y}-5$ cusp pattern without a mid-trigonid crest or other 175 distinct features (Fig. 4). As such, it is relatively simple, especially compared to other Upper 176 Paleolithic $\mathrm{M}_{3}$ s (see Bailey (2006) and Martinón-Torres et al. (2012) for mixed early modern 177 human comparative data). 
The only reliable crown morphometrics, given wear and damage, are mesiodistal and

179 buccolingual diameters for the CM 4254 and $4257 \mathrm{M}^{1} \mathrm{~s}$ and $\mathrm{M}^{2} \mathrm{~s}$, the same diameters for the CM

$1804257 \mathrm{P}^{4}$ and the CM $4258 \mathrm{M}_{2}$, and the mesiodistal diameter of the CM $4258 \mathrm{M}_{3}$ (Table S2). Even

181 so, several of those dimensions have required estimation given interproximal wear and

182 postmortem breakage (Table S2). The dimensions of the CM 4254 molars are unexceptional for

183 an E/MUP (or Upper Paleolithic) human, even if the dimensions of its $\mathrm{M}^{2}$ may be modestly

184 underestimated given postmortem damage (Fig. 5).

185 At the same time, the dimensions of CM 4257 are unusually large for the Upper

186 Paleolithic. The "area" (length $\mathrm{x}$ breadth) of the $\mathrm{P}^{4}$ is exceeded only by that of the E/MUP

187 Baousso da Torre 2. The $\mathrm{M}^{1}$ "area" is above the known Upper Paleolithic range, and the $\mathrm{M}^{2}$

188 "area" is exceeded only by that of the E/MUP Oase 2 (Fig. 5). The same pattern holds if the

189 comparative sample is Late Pleistocene, thereby including Middle Paleolithic archaic and

190 modern humans. Only the Oase $2 \mathrm{M}^{2}$ and the Baousso da Torre 2 and Neandertal Obi-Rakhmat 1

$191 \mathrm{P}^{4} \mathrm{~s}$ are larger than the Cro-Magnon 4257 teeth.

192 The dimensions of the CM 4258 molar crowns are more difficult to assess, given wear

193 and postmortem damage (Fig. 4). The more complete crown, the $\mathrm{M}_{2}$, as preserved, has

194 mesiodistal and buccolingual diameters of 12.5 and $\approx 12.0 \mathrm{~mm}$. Correcting for interproximal and

195 occlusal wear, they were likely $\approx 13.0$ and $\approx 12.5 \mathrm{~mm}$ respectively. When the respective "areas"

$196\left(\approx 150 \mathrm{~mm}^{2}\right.$ and $\left.\approx 162.5 \mathrm{~mm}^{2}\right)$ are placed in an Upper Paleolithic context (Fig. 5), the latter one is

197 beyond the comparative ranges and may well be modestly too high. But the preserved

198 (minimum) values are exceeded only by the E/MUP Předmostí 9 and Oase 1.

199 Therefore, both CM 4257 and CM 4258 have unusually large teeth. Contra Vallois and

200 Billy (1965), these dimensions are exceptional. They fall in the size range especially of the Oase

2011 and 2 molars, dentitions which have been highlighted for having very large molars for early

202 modern humans (Trinkaus et al., 2013; Trinkaus, 2018). The only Late Pleistocene $\mathrm{M}^{1}$ and $\mathrm{M}_{2}$

203 teeth with larger crowns are archaic human ones from the Middle/Late Pleistocene site of

204 Krapina (Wolpoff, 1979) and the Aterian sites of Dar-es-Soltane, El Haroura and Témara

205 (Hublin et al., 2012).

206

\subsection{Variations in Number and Position}


None of the Cro-Magnon alveoli or dental remains indicate dental agenesis or

209 supernumerary teeth. In particular, both sides of CM 4253 and 4256 and one side each of CM

2104254,4257 and 4258 indicate the presence of third molars, the most common tooth to exhibit

211 agenesis and the only one documented among E/MUP humans (Lacy, 2021). Among E/MUP

212 humans, $\mathrm{M}_{3}$ agenesis is documented for Dolní Věstonice 16 and may have been present in

213 Předmosti 3 (Matiegka, 1934; Hillson, 2006), and supernumerary teeth occurred in Dolní

214 Věstonice 15, Pataud 1 and Sunghir 2 (Hillson, 2006; Trinkaus et al., 2014; Villotte et al., 2018).

215 At the same time, the CM 4253, 4256 and 4257 alveoli indicate several orthodontic

216 alterations. The right $\mathrm{P}_{3}$ of $\mathrm{CM} 4253$ is rotated, such that the buccal side is displaced distally, and

217 the right $\mathrm{C}_{1}$ may have been as well (Figs. 1 and S4). Both $\mathrm{P}_{3}$ s of CM 4256 exhibit the same

218 rotation. In addition, the $\mathrm{I}_{2} \mathrm{~S}$ of $\mathrm{CM} 4256$ were slightly rotated with the labial portion mesially

219 displaced (Figs. 3 and S7), and its right $\mathrm{M}_{2}$ was mesially sloping, with its mesial occlusal surface

220 against the $\mathrm{M}_{1}$. These mandibular dental rotations (Table S3) are accompanied by a possible

221 rotation of the $\mathrm{CM} 4253$ left $\mathrm{P}^{3}$ and the rotated left $\mathrm{P}^{3}$ of $\mathrm{CM} 4257$. The two root sockets of the

222 latter tooth are aligned along the mesiodistal axis of the dental arcade (Figs. 4 and S8), indicating

223 a crown rotated $\approx 90^{\circ}$.

224 Rotated mandibular premolars in particular are evident in other E/MUP humans, being

225 present in Dolní Věstonice 13, 14 and 15, Muierii 1 and Pataud 1 (Hillson, 2006; Doboş et al.,

226 2010; Villotte et al., 2018). The first four are unilateral, the last is bilateral, and all involve $\mathrm{P}_{45}$.

227 All of them except Muierii 1 have the buccal side displaced mesially. Rotated $\mathrm{P}_{3}$ s are also well

228 known in both archaic and modern Middle Paleolithic humans (Rougier et al., 2006; Hillson,

229 2006; Willman et al., 2012). The etiology of rotated premolars is poorly known (Stefan, 2006),

230 but it appears to have a genetic basis (Rougier et al., 2006; McMullan and Kvam, 1990). The

231 presence of premolar rotations in three Cro-Magnon specimens, all from separate individuals

232 (see below), therefore reinforces the population coherence of the sample.

233 The CM 4258 mandible exhibits a completely impacted $\mathrm{M}_{3}$, such that its mesial occlusal

234 margin is in contact with the vertical middle of the distal $\mathbf{M}_{2}$ root below the alveolar plane (Fig.

235 4). There is a bony opening into the gingival area above the $M_{3}$ occlusal surface, but even the

236 raised distal occlusal margin did not rise above the alveolar plane. As the $\mathrm{M}_{3}$ roots are

237 completely closed, the tooth was mature and hence fully impacted. The $\mathrm{M}^{3}$ of the CM 4257

238 maxilla is not preserved. However, the distal $\mathrm{M}^{2}$ lacks an interproximal facet, there is a section 
239 of retromolar alveolar bone distal of the $\mathrm{M}^{2}$, and there is a crypt above the $\mathrm{M}^{2}$ roots of an

240 appropriate size for an $\mathrm{M}^{3}$ crown (Figs. 4, S8 and S10). As noted by Vallois and Billy (1965),

241 this cavity represents the position of an impacted $\mathrm{M}^{3}$ in this maxilla. Among E/MUP humans,

242 impacted $\mathrm{M}_{3}$ s are known for Dolní Věstonice 3, 15 and 16 (Hillson, 2006; Lacy, 2014), and

243 Pataud 1 presents an impacted $\mathrm{M}^{3}$ (Villotte et al., 2018).

\subsection{Occlusal Wear}

The extent of dental occlusal wear was first noted by Broca (1868) with reference to ages-at-death. In particular, he emphasized the marked wear (to or below the cervix) of CM 4253 and started the reference to the individual as a "veillard" (or old man). Indeed, the preserved mesial root of the right $\mathrm{M}_{1}$ appears to have been occlusally worn, suggesting tooth wear below the root bifurcation, root separation, and continued functioning of the mesial root. Yet, the right $\mathrm{M}^{2}$ retained at least some of its crown enamel (see SI S1 and Fig. S2), indicating that a number of the CM 4253 teeth retained crowns (see antemortem tooth loss below). It remains unclear to what extent the periodontal changes of CM 4253 (see below) may have affected his rates of dental wear (or vice versa).

The two preserved CM 4254 molars exhibit moderately pronounced wear, but unexceptional for a late third or fourth decade E/MUP individual. The CM 4257 and 4258 teeth, however, are markedly more worn, to similar degrees. In particular the M1s retain little of their occlusal enamel, with the CM $4258 \mathrm{M}_{1}$ having worn away the crown enamel on a portion of its circumference. Modestly more crown is present on the M2s.

There is nothing unusual in the patterns of occlusal (or interproximal) wear on these Cro-

262 wear, and assuming similar rates of wear, by ages-at-death. CM 4254 would be the youngest,

263 followed by CM 4257 and probably CM 4258, and then CM 4253 the oldest. In comparison with

264 other E/MUP individuals with dentitions and age-at-death assessments based on skeletal (non-

265 dental) aspects (e.g., Hillson et al., 2006; Trinkaus et al., 2014; de Lumley, 2016), these degrees

266 of occlusal wear suggest a range of ages-at-death for these Cro-Magnon individuals spanning the

267 fourth to the sixth decades. This implied age range is recognized to be approximate, given

268 expected variation within and between samples in rates of occlusal wear. Yet, it is sufficient to

269 provide a contrast with previous age assessments based on the auricular metamorphosis of two 
270 Cro-Magnon pelves (Gambier et al., 2006) and considerations of the degenerations of a third 271 individual (Thibeault and Villotte, 2018). Those age assessments suggest that all of the Cro-

272 Magnon individuals were at the older end of this range, in agreement with CM 4253, 4257 and 273 4258, but definitely older than CM 4254.

\subsection{Dental and Alveolar Pathology}

Discussions of the Cro-Magnon dentoalveolar paleopathology have focused primarily on the possible antemortem loss of teeth by CM 4253 and on the alveolar lesions of that individual. There have been additional comments on dental carious lesions.

\subsubsection{Antemortem Tooth Loss}

None of the alveolar remains other than CM 4253 indicate possible antemortem tooth loss (AMTL). Their preserved portions either contain teeth or portions of teeth, or they present root sockets with portions of the lamina dura indicating postmortem loss of the teeth. CM 4253, 284 in situ. however, retains extensively remodeled alveoli with only portions of a premolar and three molars

Vallois and Billy (1965) stated that an unspecified number of CM 4253's teeth were lost antemortem due to his alveolar lesions, although Broca (1868) and Pruner-Bey (1865-75) concluded that CM 4253 retained all 32 teeth until death. The same conclusion was reached by one of us (Lacy, 2014), although she inferred that some of the teeth may have been lost shortly prior to death. Reassessment of the alveoli (Table S1; SI S1 and S2; see Figs. 1, S1, S3 and S4) agrees with these conclusions. Four of the teeth (the $\mathrm{M}^{2}, \mathrm{P}_{3}, \mathrm{M}_{1}$ and $\mathrm{M}_{3}$ right) are represented by roots in situ and the $\mathrm{M}^{2}$ retained a small portion of the crown (Fig. S2). Twenty-five of the empty alveoli retain sufficient portions of their sockets, mostly with intact lamina dura, to indicate postmortem loss of the teeth. The last two teeth, the left $\mathrm{M}^{2}$, the right $\mathrm{I}_{2}$ and the left $\mathrm{M}_{1}$, are less clear. All three have alterations of their alveoli from granulomata, although each retains some portion of its root socket. Either they were lost shortly prior to death, with little time for alveolar remodeling, or they were still present but reduced in function given tenuous attachments to the alveolar bone. CM 4253 therefore had no AMTL or minor loss close to death.

As a result, the Cro-Magnon dentoalveolar remains indicate little or no AMTL, despite pronounced occlusal wear on the teeth of a least CM 4253, 4257 and 4258. In this aspect, they follow the general pattern of E/MUP dentitions. The three other complete E/MUP dental arcades 
with advanced wear - Caviglione 1, Dolní Věstonice 16 and Sunghir 1 - retained all of their teeth (Hillson, 2006; Trinkaus et al., 2014; Pinilla et al., 2016). Clear evidence of E/MUP AMTL is present on Barma Grande 4, Mladeč 1 and 8, and two isolated mandibles from Isturitz, and Brno 2 and Willendorf 2 may have each lost one tooth antemortem (Lacy, 2014).

\subsubsection{Dental Carious Lesion}

There is only one apparent lesion on the teeth, a dental carious lesion. It is a small occlusal pit into the dentin slightly to the lingual of the middle of the $\mathrm{M}_{2}$ of CM 4258 (Figs. 4 and S12), as noted by Brennan (1991) and Lacy (2014). Dental carious lesions are relatively uncommon among E/MUP individuals, having been documented on the molars of Abeilles 18985-2, Barma Grande 2, Dolní Věstonice 13 and 15, and Pavlov 1, plus three isolated teeth from Les Rois (Lacy, 2014). [Note that Pruner-Bey (1865-75) referred to alveolar osteophytic lesions as "caries"; he did not document dental carious lesions.] There is no evidence of dental enamel

313 hypoplasia, although the extent of occlusal wear may have removed evidence of these

314 developmental lesions.

\subsubsection{Periodontal Alterations}

In addition, as noted and variously described by Broca (1868), Pruner-Bey (1865-75), Vallois and Billy (1965) and Lacy (2014), the CM 4253 cranium and mandible exhibit a suite of alveolar lesions. There is general periodontal alteration through the alveoli (SI S1 and S2), and it is accompanied by three granulomata. In the maxilla, there is an area of extensive resorption on the lingual sides of the left $\mathrm{M}^{1}$ and $\mathrm{M}^{2}$ alveoli, which manifests itself as a granuloma primarily associated with the $\mathrm{M}^{2}$ (Figs. 1 and $\mathrm{S} 1$ ). In the mandible, there is a fenestration below the left $\mathrm{I}_{1}$ and $I_{2}$ (Fig. S4). It is the labial opening of a granuloma centered below the $I_{1} / I_{2}$ septum with its largest portion below the $\mathrm{I}_{1}$. There is new bone in the $\mathrm{I}_{1}$ socket and rounded trabeculae in the inferior portion of the cavity.

The primary alveolar lesion, as previously noted, is below the left $\mathrm{P}_{3}$ to $\mathrm{M}_{1}$ (SI S2; Figs. $1, \mathrm{~S} 3$ to S5). It consists of a large void in the middle and lateral corpus between the inferior alveolar nerve canal and the remaining lingual alveoli for the $\mathrm{P}_{3}$ to $\mathrm{M}_{1}$. The bone was resorbed around the roots of the $\mathrm{M}_{1}$, especially near their apices. The resorbed area continues buccally/laterally, such that the lateral portion of the corpus is absent from the alveolar margin (or where it would have been) inferiorly to the vertical middle of the corpus. The resorptive area rounds onto the lateral corpus below the $\mathrm{M}_{1}$, and the exposed trabeculae within the exposed area 
332 are rounded (see especially Fig. S5C). This area is best interpreted as a large granuloma from the $333 \mathrm{M}_{1}$. As noted above, it is unclear whether the $\mathrm{M}_{1}$ was in situ at death, given the presence of lingual root sockets, albeit with altered and resorbed bone.

The void from the left $\mathrm{M}_{1}$ granuloma continues mesially below the $\mathrm{P}_{4}$ and $\mathrm{P}_{3}$, with resorption of the buccal/lateral corpus along their roots. The void rounds onto the lateral corpus by the $\mathrm{P}_{4}$, slightly superior and distal of the mental foramen, and the bone within the void is rounded and hence resorbed. It is unclear whether the resorptive area for the $\mathrm{P}_{4}$ is an extension of the $\mathrm{M}_{1}$ granuloma or an additional one through the $\mathrm{P}_{4}$. The void around the $\mathrm{P}_{3}$ is less clear, as the margins of the void consist of both rounded resorptive surfaces, small bony growths, and broken edges. Therefore, the large left lateral mandibular void consists of either a granuloma of the $\mathrm{M}_{1}$, which spread mesially under the $\mathrm{P}_{4}$ and $\mathrm{P}_{3}$, or granulomata from the $\mathrm{M}_{1}$ and $\mathrm{P}_{4}$ (plus possibly the $\mathrm{P}_{3}$ ) that combined into a single void along the lateral corpus. A number of other E/MUP individuals exhibit granulomata, both with and without extensive occlusal wear (e.g., Barma Grande 4, Brno 2, Dolní Věstonice 16, Isturitz 4, 11 and 111, Mladeč 2 and 5457, Oreille d'Enfer 1, Pataud 1, Pavlov 1, Předmostí 21 and 26, and Sunghir 1 (Teschler-Nicola et al., 2006; Lacy, 2014; Trinkaus et al., 2006, 2014).

Cro-Magnon 4253 therefore has extensive periodontal disease, reflected in general alveolar resorption and multiple granulomata. Given the absence of all of the tooth crowns except for a small piece of the right $\mathrm{M}^{2}$, it is not possible to determine to what extent the granulomata were secondary to advanced dental wear. The alveoli of the other Cro-Magnon individuals exhibit some resorption of the preserved alveolar crests, as reflected in cervix-toalveolar crest (CAC) heights, but the advanced wear of especially CM 4257 and 4258 suggests that it may be due more to supraeruption than periodontal inflammation (see Craddock and Youngson, 2004).

Cro-Magnon 4254, 4257 and 4258 exhibit only modest amounts of alveolar remodeling from periodontal disease, to the extent that the alveolar bone is preserved. The first has little alteration around the anterior teeth, but there was some resorption around the $\mathrm{M}^{1}$ (Figs. 2 and S6). A similar situation is present for the CM 4257 maxilla, although the root exposure is primarily from postmortem bone loss (Figs. 4 and S8). The CM 4258 mandible, despite its extensive tooth wear and hence expected supraeruption, has little change in the molar alveolar margins where preserved around the $\mathrm{M}_{2}$ and the impacted $\mathrm{M}_{3}$ (Figs. 4 and S11). On the other 
363 hand, the CM 4256 mandible exhibits general resorption and rounding of the alveolar crests (Fig. 3643 and S7).

\subsection{Associations by Individual}

The cranial remains from Cro-Magnon have traditionally (Broca, 1868; Pruner-Bey 1865-75; Vallois and Billy, 1965, Villotte and Balzeau, 2018) been used to indicate the presence of four adult partial skeletons (Cro-Magnon 1 to 4) in the fossil assemblage. Based on cranial morphology, Cro-Magnon 1, 3 and 4 have been considered to be male, whereas Cro-Magnon 2 was viewed as female (i.e., Vallois and Billy, 1965). However, a reassessment of the sexes of the Cro-Magnon crania (Guyomarc'h et al., 2017) was unable to confirm these sex determinations for Cro-Magnon 2 and 3. Cro-Magnon 4 has been considered male based only on the moderately large external occipital protuberance of CM 4259 (Vallois and Billy, 1965); similarly large ones are not unusual among recent human females (Walker, 2008), making its sex ambiguous.

The recent resorting of the lower limb remains (Thibeault and Villotte, 2018) was only able to identify three pelvically sexed adults (referred to as Alpha (male), Beta (female) and Gamma (male)), although the subsequent reassessment of the upper limb remains (Villotte et al., 2020) was able to identify a fourth large adult (Delta). Their ages-at-death are elderly for Alpha and Beta and modestly younger for Gamma, but it is unknown but probably younger adult for Delta (Thibeault and Villotte, 2018; Villotte et al., 2020). In the appendicular assessments, Alpha has been linked to Cro-Magnon 1 based on sex, advanced age, carbonate coating, and systemic pathological lesions (Gambier et al., 2006; Thibeault and Villotte, 2018), but the connections between Beta to Delta and Cro-Magnon 2 to 4 have been left unresolved.

As has been accepted since the Cro-Magnon remains were first recovered, the CM 4253 cranium and mandible fit together (as Cro-Magnon 1) and show a similar degree of age-related dental and alveolar alterations. The pathological alterations of the alveoli, however, are merely advanced conditions of normal periodontal resorption combined with several granulomata, the latter most likely related to advanced tooth wear and pulpal exposure (Clarke, 1990; Alt et al., 1998).

Similarly, as noted by Pruner-Bey (1865-75), the CM 4257 and 4258 maxilla and mandible make a logical pair in several respects. They exhibit very similar degrees of occlusal and interproximal wear. Each exhibits an impacted M3. They have little evidence of periodontal 
394 disease despite their advanced dental wear. And they both have teeth that are among the largest

395 in the E/MUP and in the Late Pleistocene generally.

The CM 4254 maxillae and teeth are part of the Cro-Magnon 2 cranium, which lacks a directly associated mandible. The CM 4258 mandible does not fit with CM 4254 given the marked contrasts in molar occlusal wear and dental dimensions. The CM 4256 mandible could be associated with CM 4254; however, the periodontal resorption throughout the CM 4256 dental arcade contrast with the minimal alveolar changes of CM 4254, making a pairing of them unlikely. As a result, the dentoalveolar remains from Cro-Magnon indicate four individuals: CM 4253 (Cro-Magnon 1), CM 4254 (Cro-Magnon 2), CM 4256, and CM 4257/58.

The first two of these dentoalveolar individuals are portions of the Cro-Magnon 1 and 2 craniomandibular remains. The other two represent older individuals, based on periodontal alterations and dental wear. Each one could be associated with either Cro-Magnon 3 or 4, both of which have been considered as an older but not aged individual, albeit on the basis of suture closure (e.g., Vallois and Billy, 1965). Contra Broca (1868), Pruner-Bey (1865-75) and Vallois and Billy (1965) (Table 1), it is not possible to resolve which maxilla/mandible belongs with which of these crania.

The associations with the appendicular Alpha to Delta individuals include Cro-Magnon 1 with Alpha, but the others are less clear. The unsexed CM 4254 cranium (Cro-Magnon 2), as a

412 probable fourth decade adult based on dental wear, cannot be associated with the female Beta 413 given that the latter's age-at-death was $\geq 60$ years based on auricular metamorphosis (Gambier et 414 al., 2006). It could be linked to the male Gamma, although it is unlikely given that Gamma's 415 age-at-death was similarly assessed to be $>40$ years. Assuming that there are four adults 416 represented in the Cro-Magnon sample, CM 4254 was therefore either the same individual as 417 Delta or, unlikely, Gamma. If CM 4254 and Delta were the same individual, then CM 4256 and $4184257 / 58$ would then be the same individuals as Beta and Gamma. It is nonetheless not possible to 419 assess which of the CM 4256 and 4257/58 dentoalveolar remains would go with Beta versus 420 Gamma.

421 The most likely combinations, therefore (Fig. 6; Table S5), are CM 4253/Cro-Magnon 1 422 with Alpha and CM 4254/Cro-Magnon 2 with Delta. CM 4256 and CM 4257/58 appear equally 423 likely to associate with either Cro-Magnon 3 or 4 and with either Beta or Gamma. 


\section{Discussion and Conclusion}

This reassessment of the adult Cro-Magnon dental and alveolar remains provides additional data on their associations by individual, ages-at-death, oral health, and dental

428 dimensions and morphology. In most respects, they fall comfortably within the patterns evident 429 in other Early and Mid Upper Paleolithic remains.

These dentoalveolar remains (three mandibles, a maxilla, and two maxillae within crania)

431 indicate the presence of four adults in the sample, in agreement with the cranial and upper limb

432 remains. The CM 4253 (Cro-Magnon 1) maxilla and mandible, given their advanced dental wear 433 and periodontal changes, fit well together and with the older male postcranial remains designated 434 Alpha. The modest degree of dental wear on the CM 4254 (Cro-Magnon 2) maxilla indicates a 435 younger adult, which makes it unlikely to be associated with the older Beta and Gamma 436 postcrania and therefore, by default, associates it with the Delta upper limb remains. The CM 4374257 maxilla and 4258 mandible go together by several criteria as from an older adult. The CM 4384256 mandible does not fit with the CM 4254 maxilla given its alveolar alterations and thus 439 remains as a separate adult. It remains unclear which of the other crania (Cro-Magnon 3 and 4) 440 or postcranial sets (Beta and Gamma) go with CM 4257/58 versus with CM 4256.

The Cro-Magnon dental and alveolar remains, in combination with the Alpha to Gamma 442 postcrania, therefore indicate three older adults and one younger adult in the sample. In the 443 broader European E/MUP sample of older versus younger adults (approximately <40 and >40 444 years) (Trinkaus, 2011), the addition of these four Cro-Magnon adults provides a sample with $44532.6 \%(\mathrm{n}=43)$ older adults $(31.4 \%(\mathrm{n}=51)$ if African and Asian E/MUP remains are included $)$. 446 Although this percentage of older adults is higher than the previous value $(26.5 \%)$, it remains 447 well below the average percentage $(65.0 \%)$ for six ethnohistorical samples $(52.0 \%-80.4 \%)$, 448 below the average (39.3\%) for nine recent archeological samples, and at the bottom of the range 449 for the archeological ones (30.5\% - 48.5\%) (Trinkaus, 2011); the lowest of these recent human 450 values has been critiqued as providing a demographic, social and subsistence-related challenges 451 to the population in question (Howell, 1982; Paine and Harpending, 1998). The addition of the 452 older age profile for the Cro-Magnon adults therefore shifts the E/MUP age distribution, but the 453 E/MUP sample still exhibits the modest number of older adults present throughout the 454 Pleistocene fossil record (Trinkaus, 2011; Streeter et al., 2001). 
Although there has been emphasis on the condition of the alveoli of Cro-Magnon 1 since the early discussions of Broca (1868) and Pruner-Bey (1865-75), the indications of oral health among the Cro-Magnon adults are unexceptional for the E/MUP. Granulomata, some associated with advanced dental wear, are relatively common in the E/MUP, and periodontal disease in general was widespread in the Upper Paleolithic (Lacy, 2014). All of the Cro-Magnon adults exhibit dental calculus, as do most Pleistocene human remains. The impacted M3s of CM $4257 / 58$ do not appear to have generated any periodontal disease. These remains indicate little or no antemortem tooth loss, a condition evident in many E/MUP specimens. And the small occlusal carious lesion of CM 4258 adds to the modest number of such lesions among E/MUP humans but does not indicate serious dental decay.

The only dental features of note are the premolar rotations of CM 4253, 4256 and 4257 and the crown dimensions of the CM 4257/58 molars. Premolar rotations are moderately common among E/MUP humans, and Late Pleistocene remains in general. To the extent that they are genetically determined, they provide some unity to the Cro-Magnon sample but do not imply broader relationships among E/MUP humans. The dimensions of the CM $4254 \mathrm{M}^{1}$ and $\mathrm{M}^{2}$ are average for an Upper Paleolithic human, but those of CM 4257/58 are exceptional. The CM $4257 / 58 \mathrm{P}^{3}$ is matched by only one E/MUP specimen (Baousso da Torre 2), its $\mathrm{M}^{2}$ is exceeded only by that of Oase 2 , and its probable $\mathrm{M}^{1}$ and $\mathrm{M}_{2}$ dimensions are beyond even the very large teeth of the Oase 1 and 2 . The only Late Pleistocene $\mathrm{M}^{1}$ and $\mathrm{M}_{2}$ teeth with larger crowns are earlier Middle Paleolithic archaic human ones from Krapina and northwest African Aterian sites.

The dental and alveolar remains from the Abri de Cro-Magnon therefore contribute to the 477 further evidence on the oral health and dental configurations of Early/Mid Upper Paleolithic 478 Europeans. With the exception of the very large molars of Cro-Magnon 4257/58, these Mid 479 Upper Paleolithic remains enter comfortably into the variation of these earlier Upper Paleolithic 480 humans.

\section{Acknowledgments}

The authors thank Veronique Laborde, Aurélie Fort (curators at the Musée de l'Homme)

484 and Dominique Grimaud-Hervé (in charge of the collection) for granting access to the Cro485 Magnon remains. Funding: This research was supported by ANR Gravett'Os (ANR-15-CE33- 
0004) and the Leakey Foundation. Neither funding agency had a role in research design or

487 publication.

\section{References}

Alt, K.W., Türp, J.C., Wächter, R., 1998. Periapical lesions-clinical and anthropological aspects. in: Alt, K.W., Rösing F.W., Teschler-Nicola M. (Eds.), Dental Anthropology. Springer, Vienna. pp. 247-276. https://doi.org/10.1007/978-3-7091-7496-8_14.

Bailey, S., 2006. Beyond shovel-shaped incisors: Neandertal dental morphology in a comparative context. Periodicum Biologorum 108, 253-267.

Bräuer, G., 1988. Osteometrie. in: Knussman, R. (Ed.) Anthropologie I. Fischer, Stuttgart. pp. 160-232.

Brennan, M.U., 1991. Health and disease in the Middle and Upper Paleolithic of southwestern France: a bioarcheological study. Ph.D. Thesis. New York University.

Broca, P., 1868. Sur les crânes et ossements des Eyzies. Bull. Soc. Anthropol. Paris 3, 350-392. https://doi.org/10.3406/bmsap.1868.9548

Clarke, N.G., 1990. Periodontal defects of pulpal origin: evidence in early man. Am. J. Phys. Anthropol. 82(3), 371-376.

Craddock, H.L., Youngson, C.C., 2004. Eruptive tooth movement - the current state of knowledge. Br. Dent. J.. 197, 385-391. https://doi:10.1038/sj.bdj.4811712.

de Lumley, M.A., 2016. Estimation de l'âge au décès de “La Dame de Cavillon.” in: de Lumley, H. (Ed.), La Grotte du Cavillon sous la Falaise des Baousse Rousse, Grimaldi, Vintimille, Italie III: Étude Anatomique du Squelette de "la Dame du Cavillon.” CNRS, Paris. pp. 939-940.

Doboş, A., Soficaru, A., Trinkaus, E., 2010. The Prehistory and Paleontology of the Peştera Muierii, Romania. Étud. Rech. Archéol. Univ. Liège 124, 1-122.

Gambier, D., Brůžek, J., Schmitt, A., Houët, F., Murail, P. 2006. Révision du sexe et de l'âge au décès des fossiles de Cro-Magnon (Dordogne, France) à partir de l'os coxal. C. R. Palevol 5, 735-741. https://doi.10.1016/j.crpv.2005.12.011.

Guyomarc'h, P., Samsel, M., Courtaud, P., Mora, P., Dutailly, B., Villotte, S., 2017. New data on the paleobiology of the Gravettian individual L2A from Cussac cave (Dordogne, France) 
through a virtual approach. J. Archaeol. Sci. Rep. 14, 365-373. https://doi.org/10.1016/j.jasrep.2017.06.005.

Henry-Gambier, D., 2002. Les fossiles de Cro-Magnon (Les Eyzies-de-Tayac, Dordogne) : nouvelles données sur leur position chronologique et leur attribution culturelle. Bull. Soc. Anthropol. Paris n.s., 14, 89-112. http://bmsap.revues.org/459.

Henry-Gambier, D., Nespoulet, R., Chiotti, L., 2013. An Early Gravettian cultural attribution for the human fossils from the Cro-Magnon rock shelter (Les Eyzies-de-Tayac, Dordogne). Paleo 24, 121-138.

Hillson, S.W., 2006. Dental morphology, proportions and attrition. in: Trinkaus, E., Svoboda, J.A. (Eds.), Early Modern Human Evolution in Central Europe: The People of Dolní Věstonice and Pavlov. Oxford University Press, New York, pp. 179-223.

Hillson, S.W., Franciscus, R.G., Holliday, T.W., Trinkaus, E., 2006. The ages-at-death. in: Trinkaus, E., Svoboda, J.A. (Eds.), Early Modern Human Evolution in Central Europe: The People of Dolní Věstonice and Pavlov. Oxford University Press, New York, pp. 3145.

Howell, N., 1982. Village composition implied by paleodemographic life table: the Libben site. Am. J. Phys. Anthropol. 59, 263-269.

Hublin, J.J., Verna, C., Bailey, S., Smith, T., Olejinczak, A., Sbihi-Alaoui, F.Z., Zouak, M., 2012. Dental evidence from the Aterian human populations of Morocco. in: Hublin, J.J., McPherron, S.P. (Eds.), Modern Origins: A North African Perspective, Springer, Dordrecht, pp 189-204. https://doi.10.1007/978-94-007-2929-2_13.

Lacy, S.A., 2014. Oral Health and its Implications in Late Pleistocene Western Eurasian Humans. Ph.D.Thesis, Washington University in Saint Louis.

Lacy, S.A., (2021). Evidence of dental agenesis in Late Pleistocene Homo. Intl. J. Paleopathol. in 32, 103-110. https://doi.org/10.1016/j.ijpp.2021.01.001.

Lartet, L., 1868. Une sépulture des troglodytes du Périgord (crânes des Eyzies). Bull. Soc. Anthropol. Paris 3, 335-349. https://doi.org/10.3406/bmsap.1868.9547

Martinón-Torres, M., Bermúdez de Castro, J.M., Gómez-Robles, A., Prado-Simón, L., Arsuaga, J.L., 2012. Morphological description and comparison of the dental remains from Atapuerca-Sima de los Huesos site (Spain). J. Hum. Evol. 62, 7-58. https://doi.10.1016/j.jhevol.2011.08.007. 
Matiegka J., 1934. Homo předmostensis. Fosilní člověk z Předmostí na Moravě I. Lebky. Česká

McMullan, R.E., Kvam, E., 1990. Investigation of premolar rotation in a group of 15-year-old Norwegian children. Eur. J. Orthodont. 12, 311-315.

Paine, R.R., Harpending, H.C., 1998. Effect of sample bias on paleodemographic fertility estimates. Am. J. Phys. Anthropol. 105, 231-240. https://doi.org.10.1002/(sici)10968644.

Partiot, C., Trinkaus, E., Knüsel, C.J., Villotte, S., 2020. The Cro-Magnon babies: Morphology and mortuary implications of the Cro-Magnon immature remains. J. Archaeol. Sci. Rep. 30, 102257. https://doi.org/10.1016/j.jasrep.2020.102257.

Pinilla, B., Pérez-Pérez, A., Puech, B., Puech, P.F., Garrigue, N., 2016. Usure dentaire et mode masticatoire de "La Dame du Cavillon." Variabilité de la nourriture des hommes modernes lors du dernier maximum glaciaire. in: de Lumley, H. (Ed.), La Grotte du Cavillon sous la Falaise des Baousse Rousse, Grimaldi, Vintimille, Italie III: Étude Anatomique du Squelette de "La Dame du Cavillon." CNRS, Paris, pp. 1213-1234.

Pruner-Bey, F., 1865-75. An account of the human bones found in the cave of Cro-Magnon, in Dordogne, in: Lartet, E., Christy, H. (Eds.), Reliquiae Aquitanicae: Being Contributions to Archaeology and Palaeontology of Périgord and the Adjoining Provinces of Southern France. Williams and Norgate, London, pp. 73-92.

Rougier,. H., Crevecoeur, I., Wolpoff, M.H.., 2006. Lower third premolar rotation in the Krapina dental sample. Periodicum Biologorum 108, 269-278.

Scott, G.R., Turner, C.G. II, 1997. The Anthropology of Modern Human Teeth. Dental Morphology and its Variation in Recent Human Populations. Cambridge University Press, Cambridge UK.

Smith, B.H., 1984. Patterns of molar wear in hunter-gatherers and agriculturalists. Am. J. Phys. Anthropol. 63, 39-56.

Stefan, V.H., 2006. Rotation of the maxillary premolars: Evidence in support of premolar morphogenetic field. Dent. Anthropol. 19, 70-73.

Streeter, M., Stout, S.D., Trinkaus, E., Stringer, C.B., Roberts, M.B. \& Parfitt, S.A., 2001. Histomorphometric age assessment of the Boxgrove 1 tibial diaphysis. J. Hum. Evol. 40, 331-338. https://doi.10.1006/jhev.2001.0460. 
Teschler-Nicola, M., Czerny, C., Oliva, M., Schamall, D., \& Schultz, M., 2006. Pathological alterations and traumas in the human skeletal remains from Mladeč. in: Teschler-Nicola, M. (Ed.), Early Modern Humans at the Moravian Gate. Springer, Vienna. pp. 473-489.

Thibeault, A., Villotte, S., 2018. Disentangling Cro-Magnon: A multiproxy approach to reassociate lower limb skeletal remains and to determine the biological profiles of the adult individuals. J. Archaeol. Sci. Rep.21, 76-86. https://doi.10.1016/j.jasrep.2018.06.038.

Trinkaus, E. (2011) Late Pleistocene adult mortality patterns and modern human establishment. Proc. Natl. Acad. Sci USA 108, 1267-1271. https://doi.10.1073/pnas.1018700108. Trinkaus, E., 2018. An abundance of developmental anomalies and abnormalities in Pleistocene people. Proc. Natl. Acad. Sci. USA 115(47), 11941-11946. https://doi.10.1073/pnas.1814989115.

Trinkaus, E., Hillson, S.W., Franciscus, R.G., Holliday, T.W., 2006. Skeletal and dental paleopathology. in: Trinkaus, E., Svoboda, J.A. (Eds.), Early Modern Human Evolution in Central Europe: The People of Dolní Věstonice and Pavlov. Oxford University Press, New York, pp. 419-458.

Trinkaus, E., Bailey, S.E., Rougier, H., 2013. The dental and alveolar remains of Oase 1 and 2. in: Trinkaus, E., Constantin, S., Zilhão, J. (Eds.), Life and Death at the Peştera cu Oase. A Setting for Modern Human Emergence in Europe. Oxford University Press, New York, pp. 348-374.

Trinkaus, E., Buzhilova, A.P., Mednikova, M.B., Dobrovolskaya, M.V., 2014. The People of Sunghir: Burials, Bodies and Behavior in the Earlier Upper Paleolithic. Oxford University Press, New York.

Turner, C.G II, 1991. Scoring produces for key morphological traits of the permanent dentition: The Arizona State University dental anthropology system. in: Kelley, M.S., Larsen, C.S. (Eds.), Advances in Dental Anthropology, Wiley-Liss, New York, pp. 13-31.

Vallois, H.V., Billy, G., 1965. Nouvelles recherches sur les hommes fossiles de l'abri de CroMagnon. L'Anthropol. 69, 47-74.

Villotte, S., Balzeau, A., 2018. Que reste-t-il des hommes de Cro-Magnon 150 ans après leur découverte? Bull. Soc. Anthropol. Paris 30, 146-152. https://doi.org/10.3166/bmsap2018-0026. 
609 Villotte, S., Ogden, A.R., Trinkaus, E., 2018. Dental abnormalities and oral pathology of the

610 Pataud 1 Upper Paleolithic human. Bull. Soc. Anthropol. Paris 30, 153-161. https://doi.10.3166/bmsap-2018-0020.

612 Villotte, S., Samsel, M., Sparacello, V., 2017. The paleobiology of two adult skeletons from

613 Baousso da Torre (Bausu da Ture) (Liguria, Italy): Implications for Gravettian lifestyle. C. R. Palevol 16, 462-473. https://doi.org/10.1016/j.crpv.2016.09.004.

615 Villotte, S., Thibeault, A., Sparacello, V., Trinkaus, E., 2020. Disentangling Cro-Magnon: The 616 adult upper limb skeleton. J. Archaeol. Sci. Rep.33, 102475. https://doi.org/10.1016/j.jasrep.2020.102475.

618 Walker, P.L., 2008. Sexing skulls using discriminant function analysis of visually assessed traits. 619 Am. J. Phys. Anthropol. 136,39-50. https://doi.10.1002/ajpa.20776.

620 Willman, J.C., Maki, J., Bayle, P., Trinkaus, E., Zilhão, J., 2012. Middle Paleolithic human remains from the Gruta da Oliveira (Torres Nova), Portugal. Am. J. Phys. Anthropol.

623 Wolpoff MH. 1979. The Krapina dental remains. Am. J. Phys. Anthropol. 50, 67-114.

624 Wood, B., Abbott, S., 1983. Analysis of the dental morphology of Plio-Pleistocene hominids. I. 625 Mandibular molars: crown area measurements and morphological traits. J. Anat. 136, 626 197-219. 


\section{Captions to the Figures}

630 Figure 1. Occlusal views of the Cro-Magnon 4253 (Cro-Magnon 1) maxillae (above) and 631 mandible (below). The maxillary alveoli are encrusted with thin carbonate. The mandibular

632 alveoli have sustained some erosion, especially lingually by the molars, and the left buccal

633 alveolus is extensively resorbed from an $\mathrm{M}_{1}$-centered granuloma. Portions of teeth are present for

634 the right $\mathrm{M}^{2}$ and the right $\mathrm{P}_{3}$ and $\mathrm{M}_{1}$.

Figure 2. Occlusal view of the Cro-Magnon 4254 (Cro-Magnon 2) maxillae.

Figure 3. Occlusal view of the Cro-Magnon 4256 mandibular corpus. Portions of the roots are 639 preserved for the left $\mathrm{I}_{1}$ and both $\mathrm{P}_{3} \mathrm{~s}$.

641 Figure 4. The Cro-Magnon 4257 left maxilla in occlusal and buccal views (above) and the Cro642 Magnon 4258 right mandible in medial and occlusal views (below). Note that the CM $4257 \mathrm{P}^{3}$ 643 does not fit into the left maxilla, and it probably represents the right $\mathrm{P}^{3}$ of the same individual 644 (see Fig. S8).

646 Figure 5. The maxillary $\mathrm{P}^{4}, \mathrm{M}^{1}$ and $\mathrm{M}^{2}$ and mandibular $\mathrm{M}_{2}$ crown "areas" (length $\mathrm{x}$ breadth) for

647 Cro-Magnon 4254, 4257 and 4258 compared to boxplot distributions of European Upper

648 Paleolithic samples: E/MUP: Early and Mid Upper Paleolithic; LUP: Late Upper Paleolithic.

649 Samples sizes are: E/MUP: 26, 49, 42 and 43; LUP: 5, 13, 11 and 12 for the $\mathrm{P}^{4}, \mathrm{M}^{1}, \mathrm{M}^{2}$ and $\mathrm{M}_{2}$

650 respectively. The E/MUP high outlier in the $\mathrm{M}^{1}$ and especially the $\mathrm{M}^{2}$ plots is Oase 2 (Trinkaus 651 et al., 2013); the high E/MUP $\mathrm{P}^{4}$ value is Baousso da Torre (Bausu da Ture) 2 (Villotte et al., 652 2017). The two values for CM $4258 \mathrm{M}_{2}$ are the minimum "area" (4258a) and the estimated 653 "area" (4258b); the high E/MUP M2 values are Předmostí 9 and Oase 1 (Matiegka, 1934;

654 Trinkaus et al., 2013).

656 Figure 6. Probable and possible associations of the Cro-Magnon dentoalveolar remains (middle) 657 with the numbered crania (left) and the appendicular sets (right). 

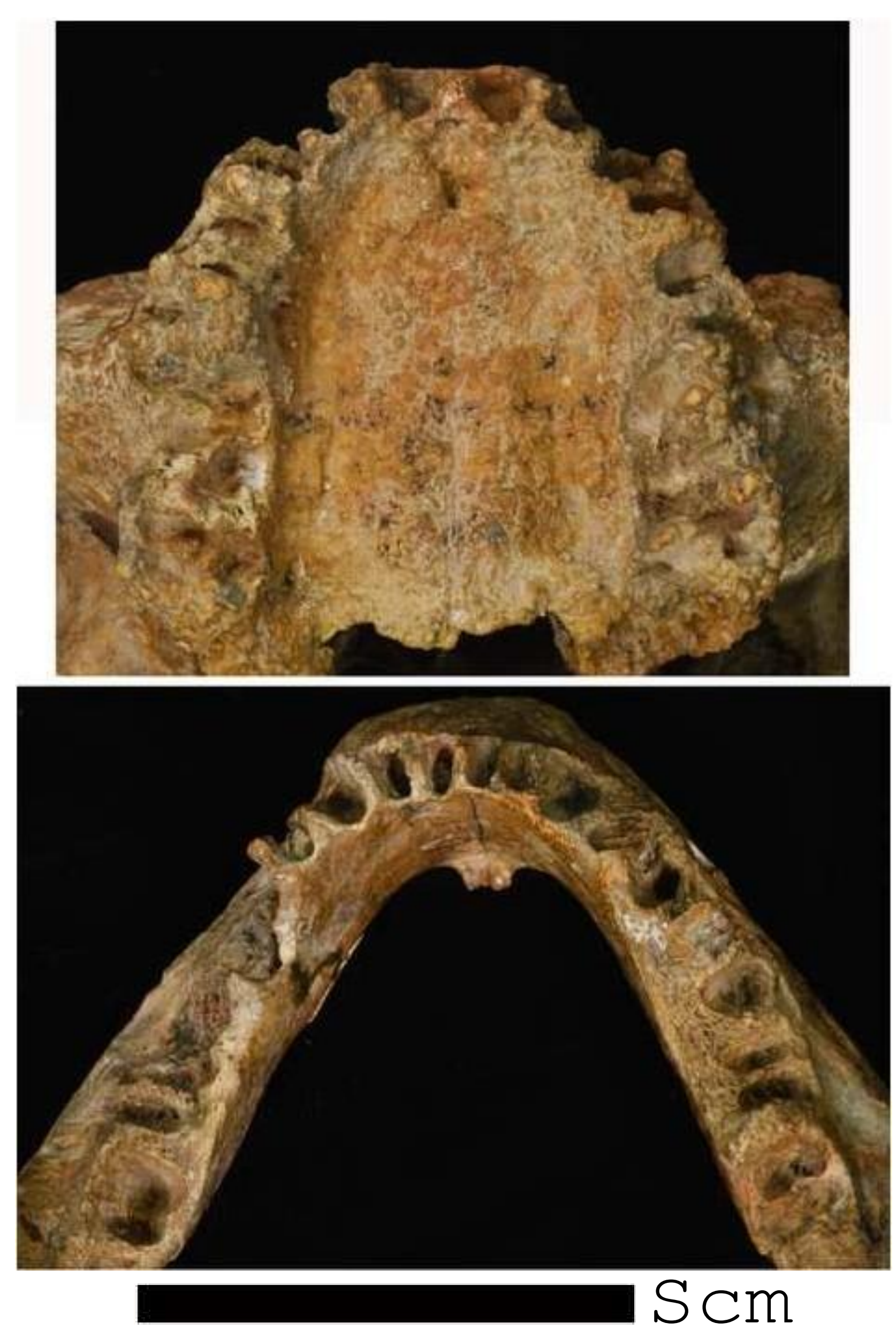


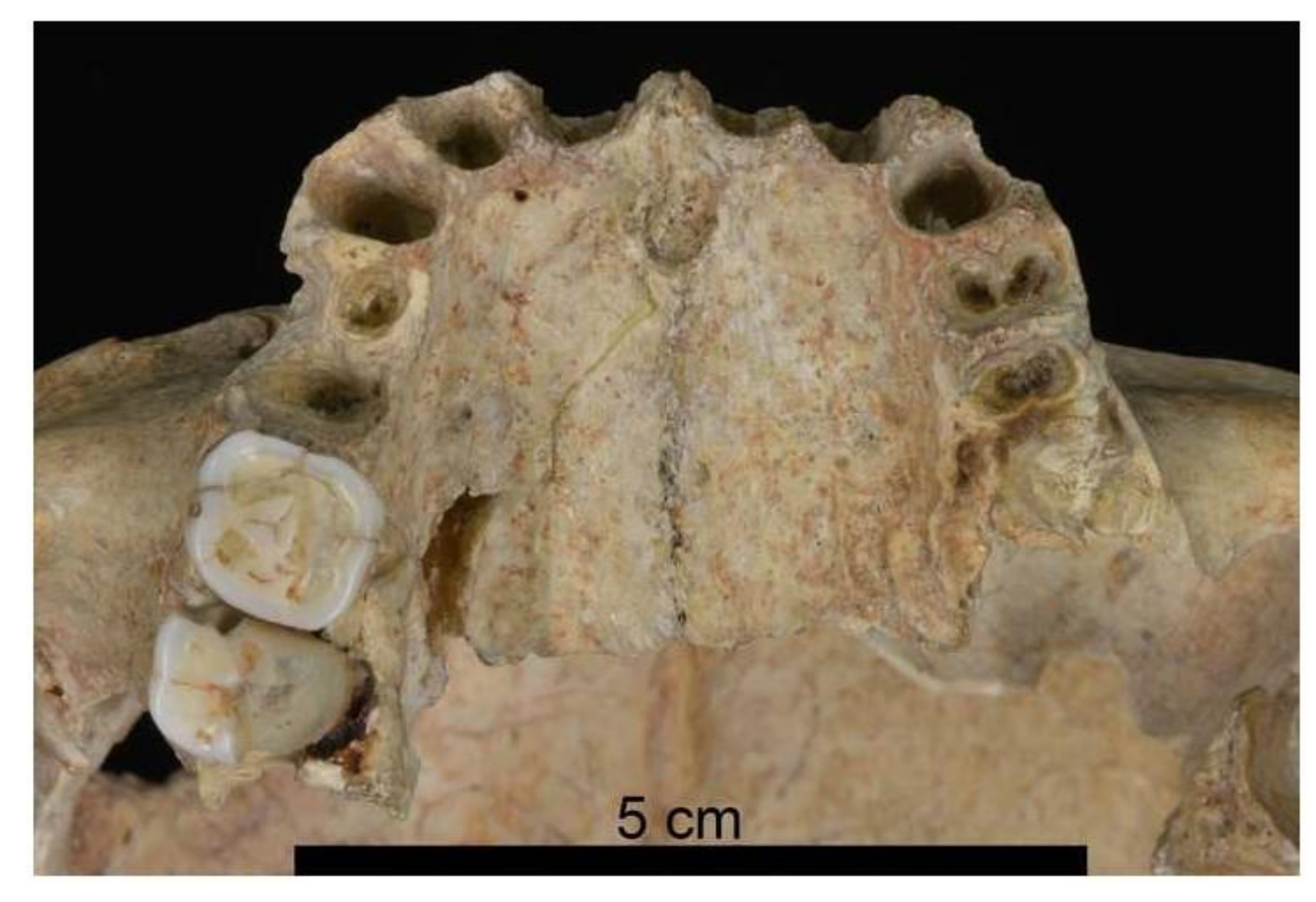



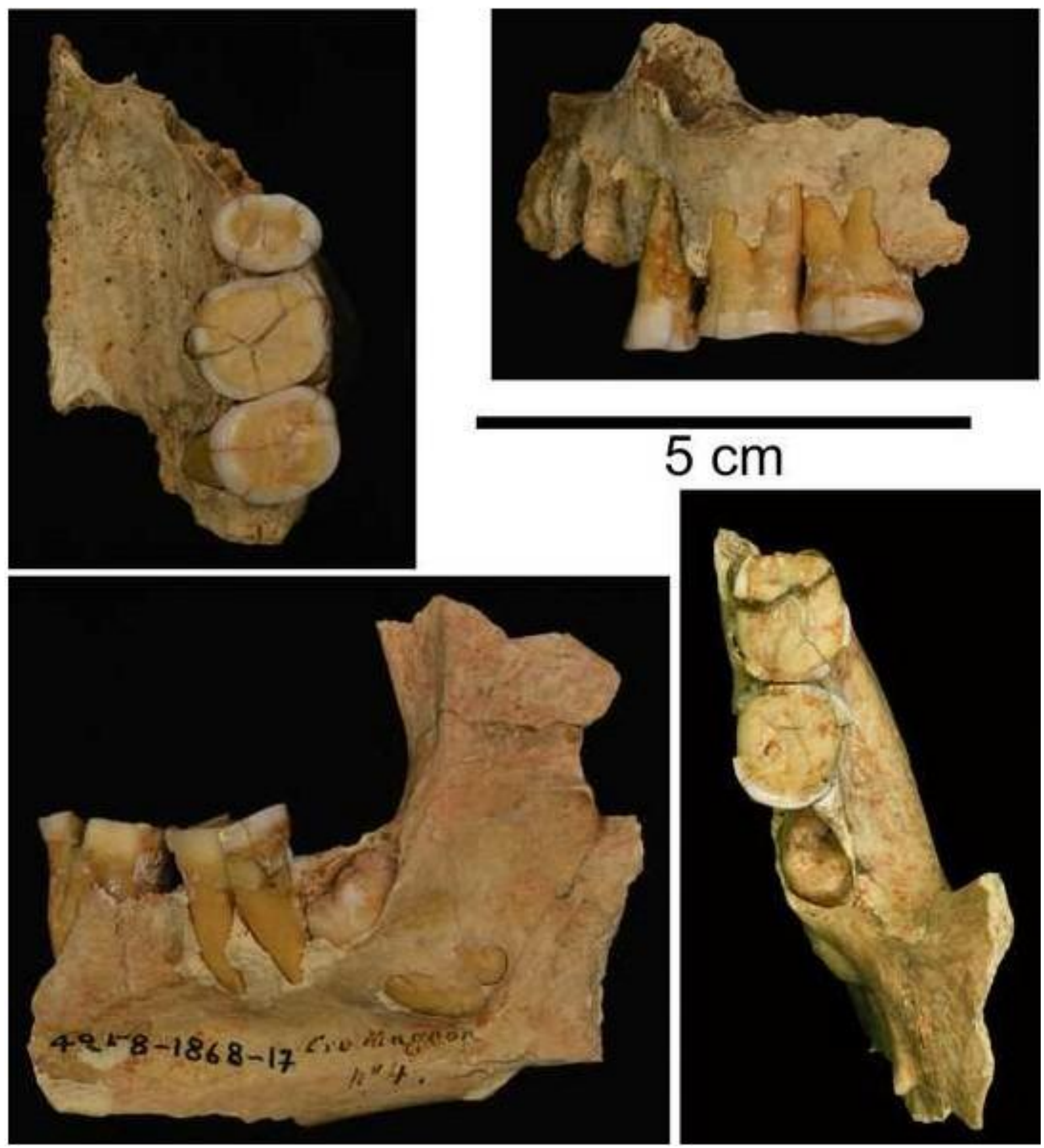

$5 \mathrm{~cm}$

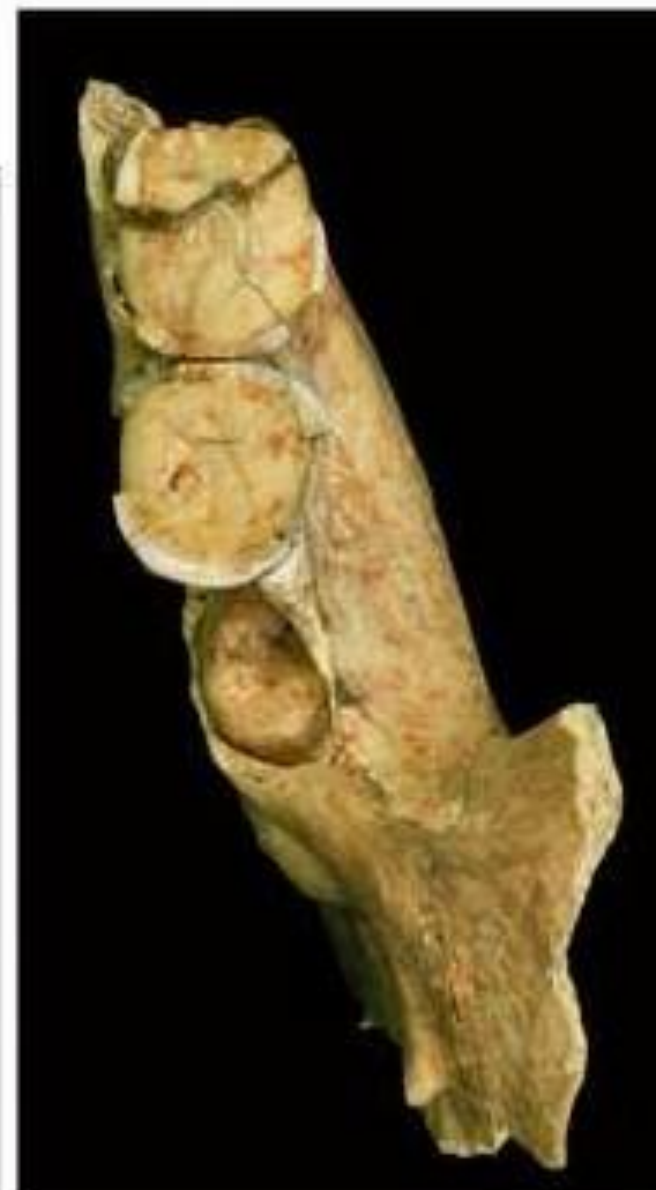



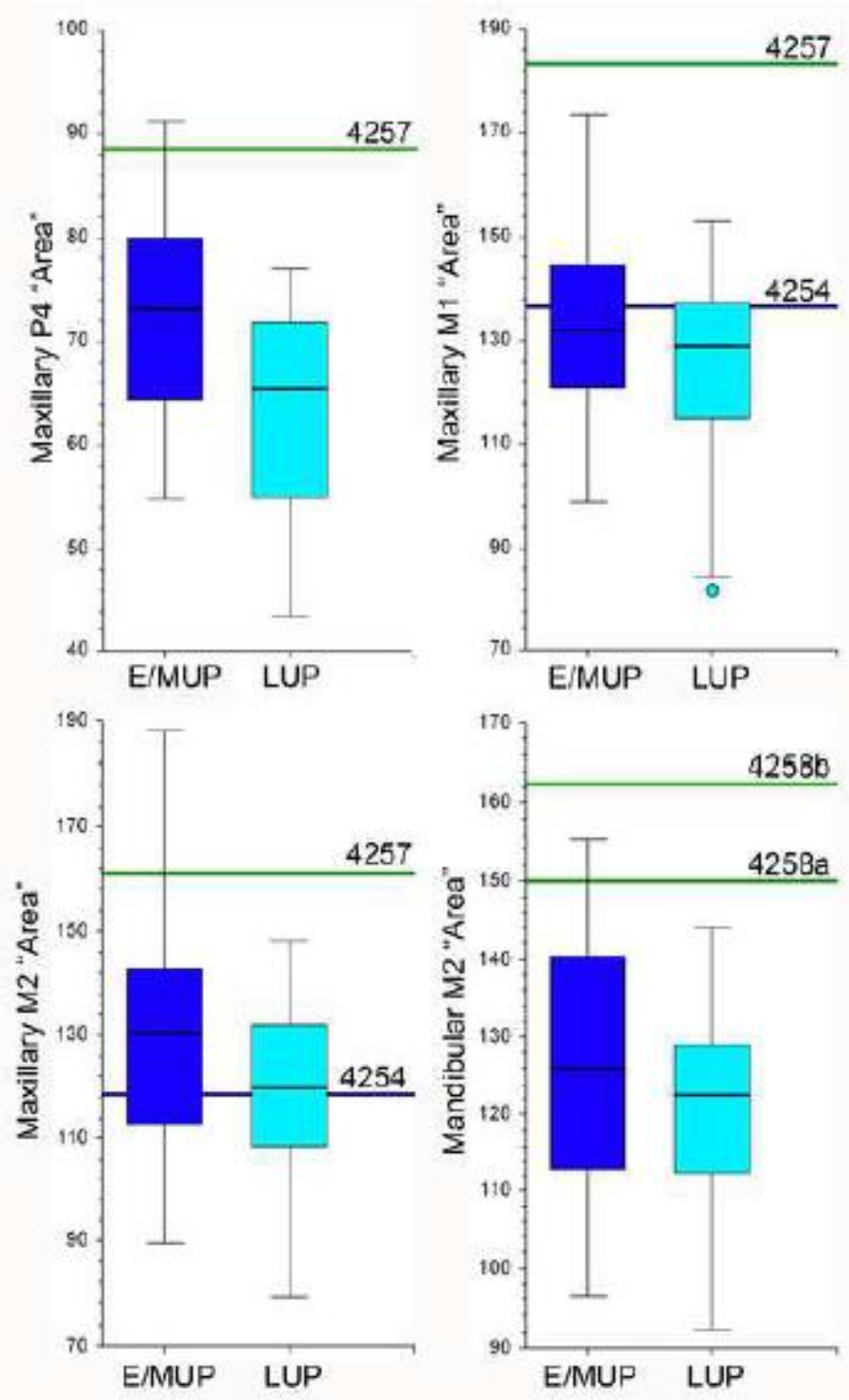
Cro-Magnon 1 CM 4253 Alpha

Cro-Magnon 2 CM 4254

Delta

Cro-Magnon $3 \longleftarrow$ CM 4256

Gamma

Cro-Magnon $4-C M$ 4257/58

Beta 


\section{Author contributions:}

Erik Trinkaus: Conceptualization, Data curation, Investigation, Methodology, Visualization, Writing - original draft. Sarah A. Lacy: Funding acquisition, Data curation, Investigation, Methodology, Writing-review \& editing. Adrien Thibeault: Methodology, Visualization, Writing-review \& editing. Sébastien Villotte: Conceptualization, Funding acquisition, Investigation, Project administration, Resources, Writing-review \& editing. 


\section{S1: Cro-Magnon 4253 (Cro-Magnon 1) Maxillary Dentoalveolar Remains}

All of the Cro-Magnon 1 maxillary alveoli are encrusted with a thin layer of carbonate, which contains "pearls" of concretions, especially in the postcanine areas. The observations are based on visual assessment of the original specimen combined with a CT slice of the maxilla (Figs. S1 and S3).

Except as noted otherwise for molars, all of the sockets appear normal without the resorption associated with antemortem tooth loss, despite damage to the alveolar margins. The incisors, canines and premolars are therefore inferred to have been lost postmortem. Three of the teeth, the left $\mathrm{P}^{3}$ and the right $\mathrm{C}_{1}$ and $\mathrm{P}_{3}$, were rotated and/or appear to have been rotated (Table S3).
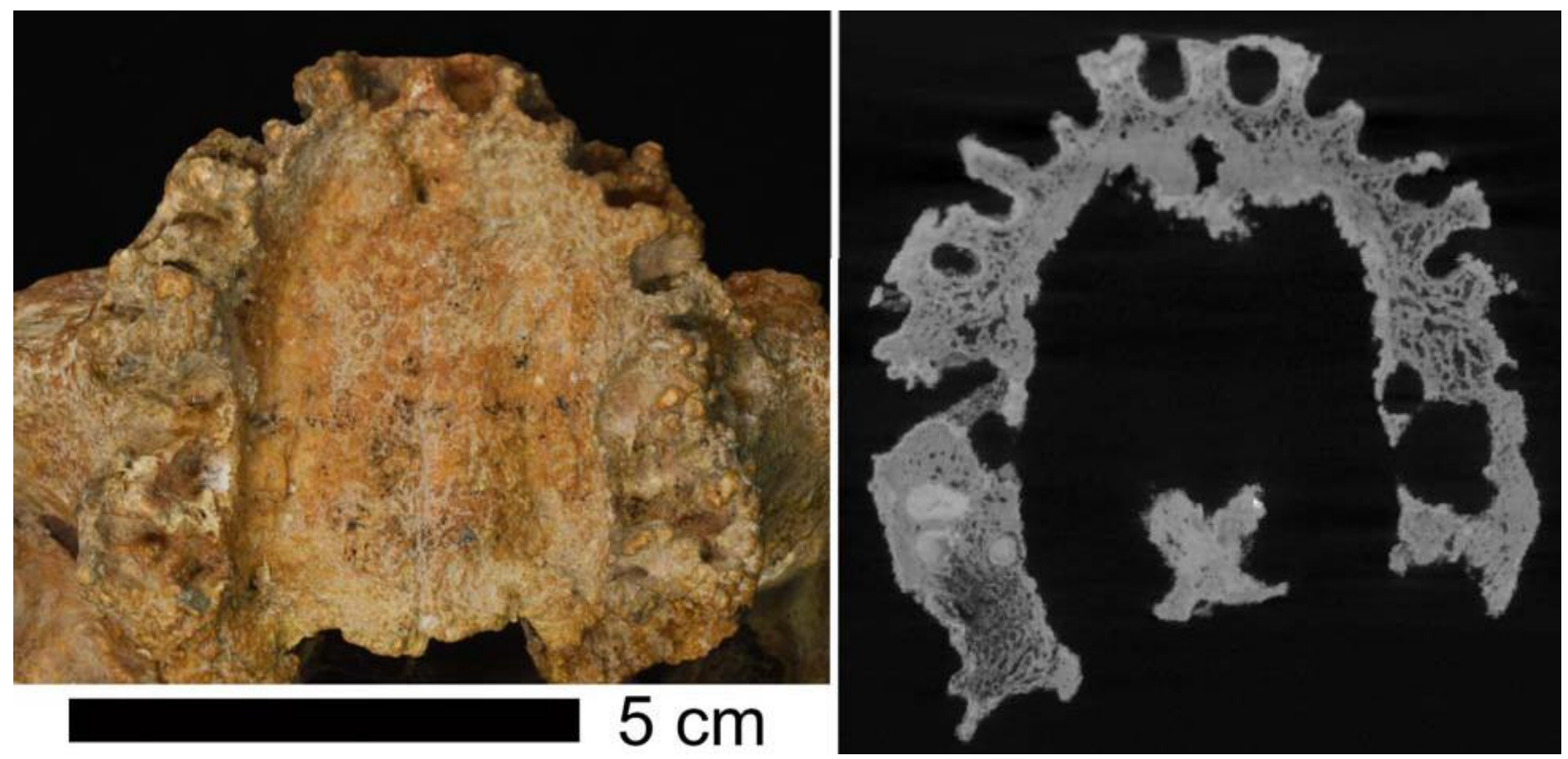

Figure S1. Occlusal view of the Cro-Magnon 4253 maxillae (left) and horizontal CT slice through the alveoli of the maxillae (right). There are also palatine ridges along the intermaxillary suture, whose developmental basis remains unclear (Léonard et al., 2014)

\section{$I^{l}$ Right}

There is a largely complete alveolus lacking the labial margin.

$$
I^{1} \text { Left }
$$

The alveolus is essentially complete. 
The lingual half of the alveolus remains with a portion of the mesial side. Carbonate partially filling the mesial side of the socket.

$I^{2}$ Left

The lingual and mesial sides of the alveolus are present.

\section{$C^{l}$ Right}

The alveolus is open mesially and labially. The root is tilted such that its apex points distally. based on the lingual side of the socket.

\section{$C^{l}$ Left}

Primarily the lingual side of the tooth socket is preserved. The lingual socket, and hence the root, is angled superior-distally to occlusal-mesially more than the right one.

$P^{3}$ Right

A normal and largely preserved socket is vertically set in maxilla. It appears radiographically to have been single rooted.

$P^{3}$ Left

It appears as a normal, mesiodistally compressed socket, open buccally but intact, especially lingually and distally. The socket slants superior-distally to occlusal-mesially, along with the left $\mathrm{C}^{1}$. It appears radiographically to have been single rooted. The lingual root is also displaced slightly mesially, suggesting some mesiolingual to distobuccal rotation of the tooth.

$P^{4}$ Right

The alveolus is visually obscured, but radiographically the socket appears normal and single rooted.

$P^{4}$ Left

The tooth socket is broken open buccally and partially distally. The socket, and hence the root, slants superior-distally to occlusal-mesially, along with the left $\mathrm{C}^{1}$ and $\mathrm{P}^{3}$. $M^{1}$ Right

The alveolus of the right $\mathrm{M}^{1}$ is damaged lingually and buccally, but it exhibits the apex area and most of the mesial side of the lingual root socket, and an open area for the distobuccal root. The area of the mesiobuccal root is less apparent, but it is likely represented by a buccal depression evident especially radiographically.

$M^{1}$ Left

There is buccal exposure of both buccal root sockets and lingual exposure of the lingual root socket. All three sockets (hence roots) appear to have been complete, although the distal side of the lingual root socket appears to have been partially resorbed (see $\mathrm{M}^{2}$ left). All of the 75 root sockets slant mesially, such that the whole tooth would have been markedly tilted mesially. 
For the mesiobuccal root, its angle to the approximate alveolar plane is $40^{\circ}-55^{\circ}$. The condition of the sockets indicates postmortem loss despite the lingual alveolar resorption.

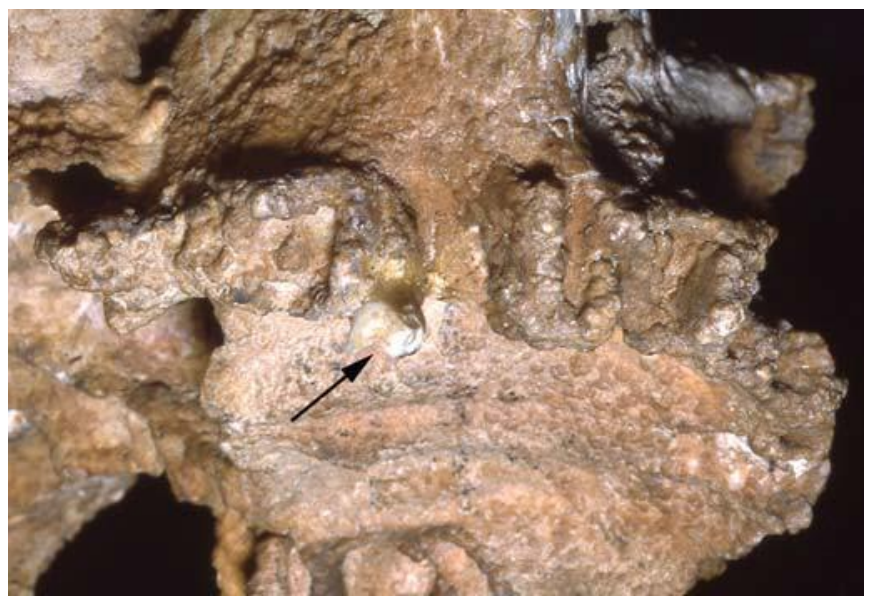

Figure S2. The Cro-Magnon 4253 right maxillary alveolus and dentition, with the originally remaining portion of the $\mathrm{M}^{2}$ exhibiting crown enamel preservation.

$M^{2}$ Right

The right $\mathrm{M}^{2}$ was in situ at death. The normal three roots are evident in the radiographic slice, and there is a portion of the mesiolingual cervix exposed currently. However, at least in 1985 (when photographed by ET), the mesiolingual corner of the crown extended to the occlusal surface, retaining at least $2 \mathrm{~mm}$ of the crown height (Fig. S2). It is therefore inferred that most, if not all of the crown, was present and functioning at the time of death.

$M^{2}$ Left

The $\mathrm{M}^{2}$ socket is an open, irregularly circular cavity about $\approx 9 \mathrm{~mm}$ in diameter. There is nonetheless a buccal groove for the distobuccal root at its distobuccal corner, but otherwise the void is irregularly smooth or at least without root indications. The lingual side is open, continuing distally the resorption on the lingual side of the $\mathrm{M}^{1}$ lingual root alveolus. The $\mathrm{M}^{2}$ buccal alveolus side retains its bony wall.

The tooth therefore appears to have had a large lingual granuloma, especially around the lingual and mesiobuccal roots, The tooth may have been lost antemortem, but if so, shortly prior to death. Alternatively, the tooth was retained by the distobuccal root but reduced in function.

$M^{3}$ Right

The tooth is absent, but in occlusal view the alveolus is evident with the clear apical sockets for the three roots with short septa between the depressions. The $\mathrm{M}^{3}$ was therefore threerooted and apparently lost postmortem..

$M^{3}$ Left

The area of the left $\mathrm{M}^{3}$ retains (in matrix) buccal bone for its alveolus and what appear to be small sockets for three roots. The two buccal sockets are separate but very close together, and the lingual one is very separate and displaced distally of the distobuccal root. It appears that the tooth was present at death, but that it was altered in position. 

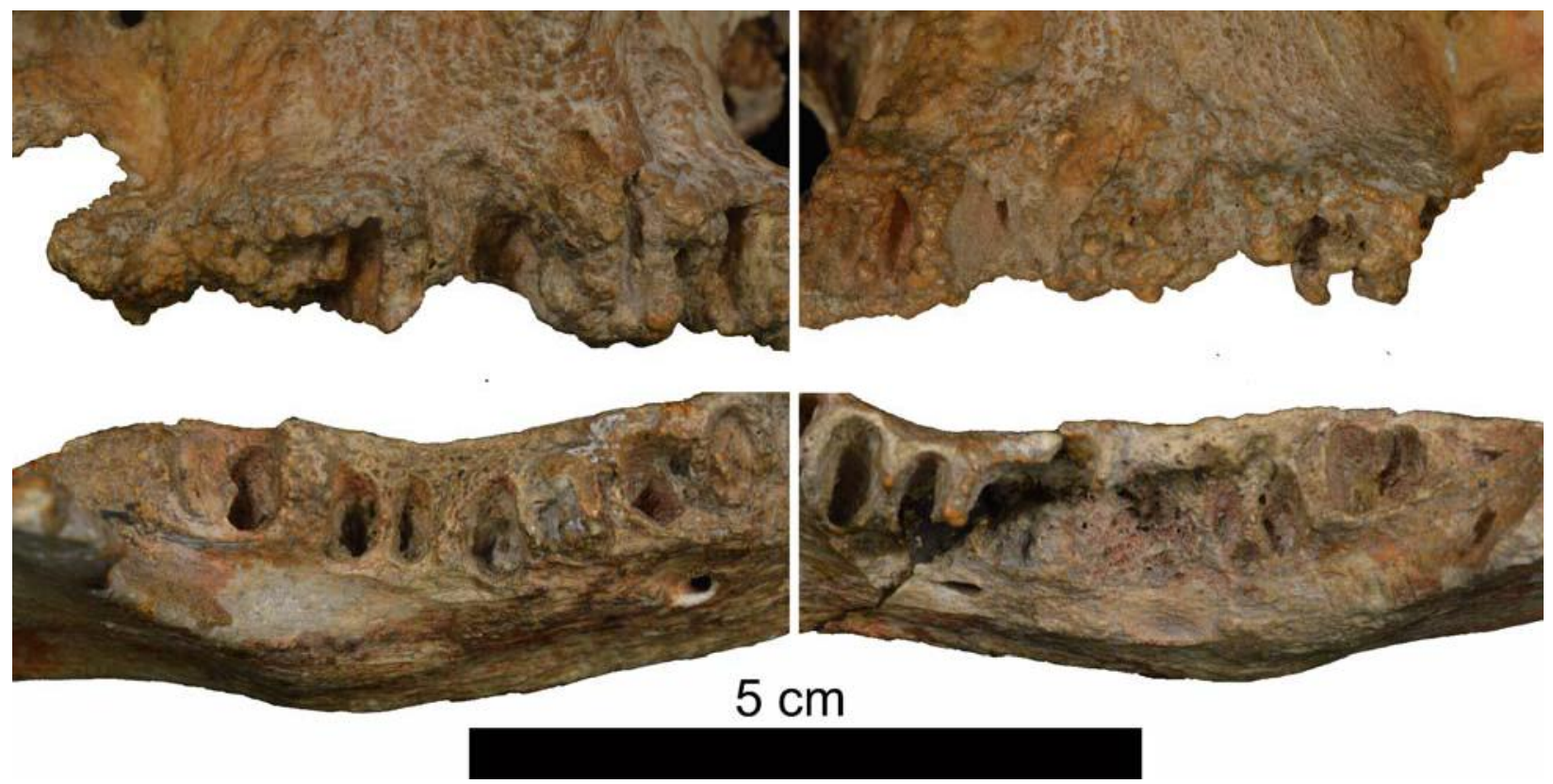

112

113

114

115

116

117

118

119

120

121

122

123

124

125

126

127

128

129

130

131

132

133

134

135

136

137

138

139

Figure S3. The premolar and molar alveoli of Cro-Magnon 4253 in bucco-occlusal views. The maxillary arcades are above and the right sides are to the left. Note the large resorptive area of the left mandibular $\mathrm{M}_{1}$ area, and the remains of the right $\mathrm{P}_{3}$, mesial $\mathrm{M}_{1}$ and distal $\mathrm{M}_{3}$ roots.

\section{S2: Cro-Magnon 4253 (Cro-Magnon 1) Mandibular Dentoalveolar Remains}

The mandibular alveoli lack the carbonate encrustation of the maxillary alveoli. However, most of them sustained postmortem erosion, especially labially by the anterior teeth and lingually along the postcanine teeth (Figs. S3 and S4). The preserved dental remains consist of portions of the right $\mathrm{P}_{3}$ root, the right $\mathrm{M}_{1}$ mesial root, and the right $\mathrm{M}_{3}$ distal root.

There was extensive antemortem resorption buccally by the left $\mathrm{P}_{4}$ and $\mathrm{M}_{1}$ with possible antemortem tooth loss, and the right $\mathrm{I}_{2}$ socket apex contains a bony growth suggesting antemortem tooth loss (see below). All of the other alveoli indicate postmortem loss of the teeth.

\section{Il Right}

The root socket has the lingual and mesial alveolar margins intact. The other alveolar margins are largely eroded.

\section{Left}

The left $\mathrm{I}_{1}$ preserves a complete socket with eroded alveolar margins. The apex of the socket opens into a granuloma that has its largest portion and opening below the left I1 (Fig. S4). The anterior/labial opening of the granuloma has been broken superiorly and distally, but the core of the fenestration and its mesial and inferior margins are the original bone. The fenestration is $4.8 \mathrm{~mm}$ wide, currently $9.1 \mathrm{~mm}$ high, but originally $4.5-5.0 \mathrm{~mm}$ high. The interior 
of the granuloma has new bone laid down up into $\mathrm{I}_{1}$ left socket, but mostly rounded trabeculae are exposed in lower portion of it.
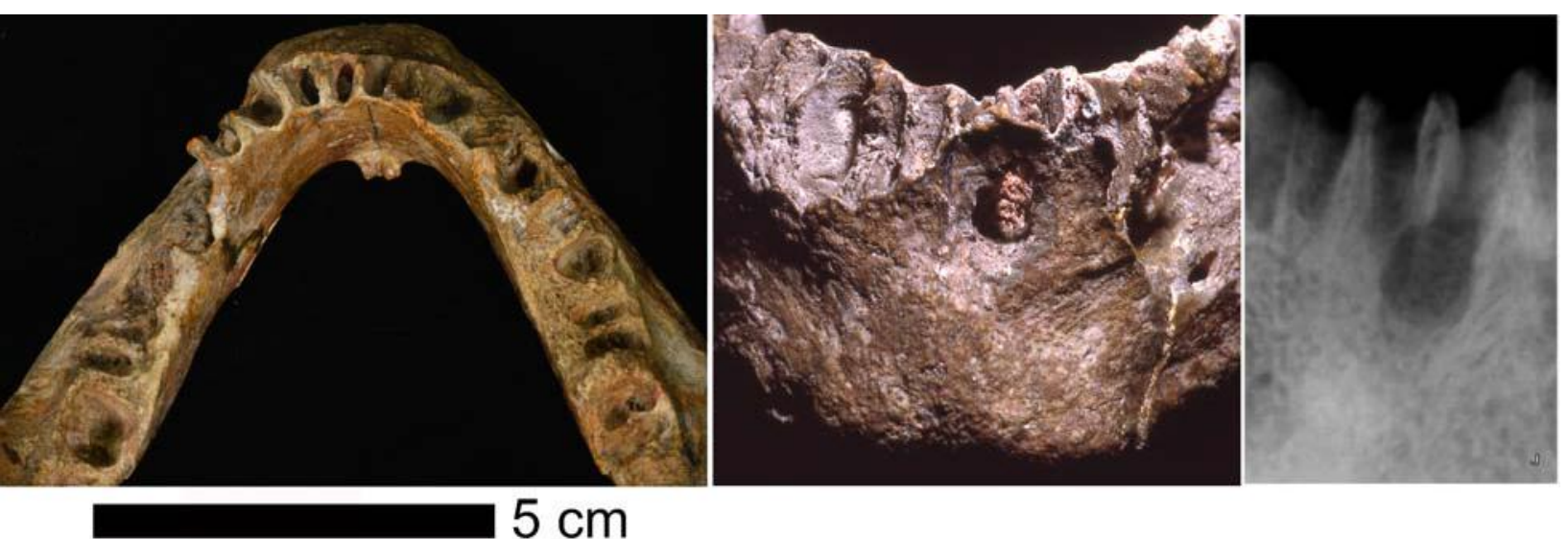

Figure S4. The Cro-Magnon 4253 Mandible in occlusal view (left), detail of the anterior alveoli (middle) with the granuloma fenestration below the left incisors, and radiograph of the incisor granuloma (right). Scale for the superior view only.

\section{$I_{2}$ Right}

The socket consists of a lingual margin and the lower portion of the $\mathrm{I}_{1 / 2}$ septum, with loss of the labial and distal margins of the socket. There is an expansion of the apical region of the socket partly filled with matrix distally, but the middle portion has a bony growth within it. Therefore, the tooth was probably lost shortly before death, with only partial remodeling of the socket and a bony growth around the apex of the socket.

\section{I2 Left}

The tooth socket is complete with the labial midline and mesial septum lower than the distal $\mathrm{I}_{2}$ septum. The apex opens in a moderately large granuloma that is below the $\mathrm{I}_{1} / \mathrm{I}_{2}$ septum and enlarged primarily below the $\mathrm{I}_{1}$ socket (see left $\mathrm{I}_{1}$ ).

\section{$C_{1}$ Right}

The lingual socket remains with intact lamina dura. It has lost of all but a small superior the lingual edge of the mesial $\left(\mathrm{I}_{2} / \mathrm{C}_{1}\right)$ septum, but most of the lingual margin and two-thirds of the distal septum with lamina dura are preserved. All of the labial socket is gone except for the lower few millimeters to the apex. The labial edge is rounded with tiny knobs of bone, and therefore the labial alveolus was resorbed with the tooth in place. The preserved deeper portion of the tooth socket suggests some mesiolingual to distobuccal rotation of the root, similar to the right $\mathrm{P}_{3}$, but its extent is unclear given the labial alveolar damage.

\section{$C_{1}$ Left}

The largely complete socket is preserved with the mesial, lingual and distal walls presenting with clean lamina dura. Almost all of the labial wall is absent; the edges appear broken, but they are rounded and there are small growths of bone on them especially around the inferior half of the socket. Therefore, the tooth was in situ, but there was resorption of the labial 
wall. The maximum height of the socket is $15.3 \mathrm{~mm}$, but only $\approx 1.5 \mathrm{~mm}$ remained on the labial side.

$P_{3}-M_{1} L e f t$

There is a large void below the left $\mathrm{P}_{3}$ and $\mathrm{P}_{4}$, back to the $\mathrm{M}_{1}$ (Figs. S3 to S5). The bone is clearly resorbed where the $\mathrm{M}_{1}$ should be, especially at the bottoms of the root sockets and the buccal side, with a rounding out onto the lateral corpus. The buccal/lateral bone is broken below the $\mathrm{P}_{3}$ and partially broken below the $\mathrm{P}_{4}$, and it is unclear to what extent the large void below the $\mathrm{P}_{3}$ and $\mathrm{P}_{4}$ is resorption versus breakage.

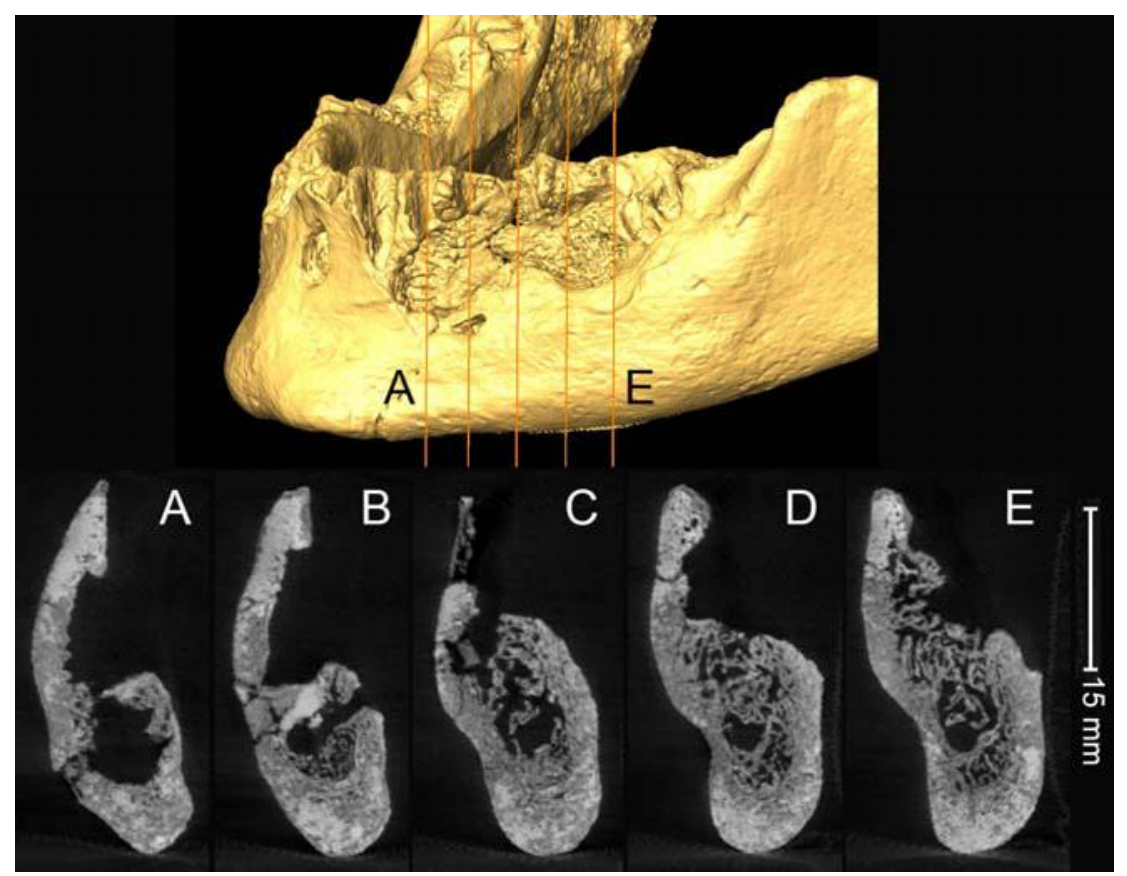

Figure S5. Above: anterolateral virtual reconstruction of the Cro-Magnon 4253 left mandibular corpus with the positions (A to E) of the CT slices through the $\mathrm{P}_{3}$ to $\mathrm{M}_{1}$ resorptive area. Below: the CT slices (lateral to the right) through the damaged and pathologically resorbed area of the mandible.

\section{$P_{3}$ Right}

The socket is present and contains the broken root. The alveolar margin is intact lingually, but it slopes down buccally such that the it is $\approx 10 \mathrm{~mm}$ lower buccally. The same small buccal growths are present as with the $\mathrm{C}_{1}$. The root is rotated such that it is oriented mesiolingual to distobuccal.

\section{$P_{3}$ Left}

The superior $10.4 \mathrm{~mm}$ of the lamina dura is present mesially and $6.7 \mathrm{~mm}$ of it distally with the appropriate septa for the root sides, along with $8.2 \mathrm{~mm}$ of the lingual socket with its lamina dura. The adjacent lateral wall is absent, but its lateral edges have rows of small bony growths, and hence there was resorption of the buccal wall antemortem. The remainder of the root socket would have been within the lateral corporeal void, which has broken edges. The $\mathrm{P}_{3}$ 
therefore sustained buccal socket resorption, possibly extending interiorly to its apex, but the tooth remained in situ.

\section{$P_{4}$ Right}

The single rooted socket is mostly preserved with the buccal margin lower by 7.8 than the lingual one; the adjacent septa slope down from the largely normal lingual alveolar margin. There is the same rounding of the edges as with the $\mathrm{P}_{3}$. The socket is broken within the mesial side, but the lamina dura appears mostly normal.

$P_{4}$ Left

The socket and its lamina dura are preserved only on the mesial septum with $\mathrm{P}_{3}$ and on the mesial half of the lingual side. The distal and buccal sides are absent. There is a large void under the preserved portion. Approximately where the root apex should be ends in irregular rounded bone that rounds out onto the lateral corpus. This portion of the reworked bone is just superior and just distal of the mental foramen. The preservation of mesial and lingual lamina dura suggests that the tooth was at least tenuously in situ at death, even through most of its socket was resorbed.

\section{$M_{1}$ Right}

The lingual alveolar margin is eroded, but the root sockets and the buccal side are intact, with resorption of the buccal alveolus. The mesial root socket retains the broken mesial and lingual portions of the mesial root in place. It is unclear whether the mesial root was merely broken postmortem and eroded (as is most of the mandible), or whether it was worn down to the root, with the consequent separation of the two roots. The distal root socket is empty and had expanded around the superior alveolar margin, with a tiny raised lip of bone buccally. It is unclear whether the distal root was lost antemortem, after separation from the mesial root and resorption around the socket, or if it was lost postmortem.

$M_{1}$ Left

The only remaining portion of the left $\mathrm{M}_{1}$ socket is a distolingual and lingual section for the mesial root. For the distolingual corner, there is a small area $5.7 \mathrm{~mm}$ obliquely wide and 7.6 $\mathrm{mm}$ high at the alveolar margin. The lateral margin of it distally is a rounded small bony growth. The small portion of the original lingual alveolar margin is rounded and reduced in height. The margin is $4.6 \mathrm{~mm}$ thick, and $5.6 \mathrm{~mm}$ high. It lacks the lamina dura and exhibits soft and porous bone.

Below these portions of mesial root socket is a void, which ends inferiorly in a large area of irregular, rounded trabecular bone. The fossa is $9.7 \mathrm{~mm}$ wide and $10.9 \mathrm{~mm}$ mesiodistally, with the lowest point distal. It is not possible to discern root apices within it. The bottom of the area rounds out onto the lateral corpus, with a strip of cortical bone $6 \mathrm{~mm}$ wide with a small lip laterally demarcating it.

The distal $\mathrm{P}_{4}$ / mesial $\mathrm{M}_{1}$ septum is completely absent. The mesial $\mathrm{M}_{2} /$ distal $\mathrm{M}_{1}$ septum consists of a small and sharp ridge along the mesial edge of the $\mathrm{M}_{2}$ mesial root apical socket. These aspects reflect a large granuloma that resulted in the resorption of the mesial, distal and buccal $\mathrm{M}_{1}$ socket, and then rounding off of the remaining bone. It secondarily involved the $\mathrm{P}_{4}$ and less so the $\mathrm{M}_{2}$. It remains uncertain whether the small piece of porous bone on the lingual mesial root socket indicates that the tooth was still in situ at death. 
The alveolus presents complete double root sockets with a normal interradicular septum. The lamina dura is intact. Although slightly broken, the buccal alveolar margin was partially resorbed. The lingual alveolus was broken postmortem. The $\mathrm{M}_{2} / \mathrm{M}_{3}$ septum is thickened across its width to $4.8 \mathrm{~mm}$.

\section{$M_{2}$ Left}

The lingual alveolar border was slightly reduced and thickened to $4.2 \mathrm{~mm}$, but the buccal alveolar margin was reduced down to the level of the lateral eminence. The mesial septum is largely absent, reduced to a thin edge that barely projects (see left $\mathrm{M}_{1}$ ). The $\mathrm{M}_{2} / \mathrm{M}_{3}$ septum is thickened, $3.0 \mathrm{~mm}$ in its middle, and it is high, probably close to the original alveolar height. The interroot septum is high and $1.4 \mathrm{~mm}$ thick, somewhat below the preserved lingual alveolar margin. The lamina dura where present is largely intact, but there is porosity towards the apex and on the lingual side of the distal root socket. The combination of features suggests a tooth tilted modestly towards the absent $\mathrm{M}_{1}$, in the aftermath of the $\mathrm{M}_{1}$ loss.

\section{M3 Right}

There is an intact socket with the distal root in place; it was broken off at the lingual alveolar level. There was a clear separation of the two roots, but with a thin interradicular septum. The higher alveolar areas mesial and distal of the socket should both be close to the original "healthy" alveolar level. The lingual and buccal alveoli, however, are resorbed.

\section{$M_{3}$ Left}

The socket presents intact lamina dura with minimal fine porosity near the apex. There is modest reduction of the lingual alveolus and into the retromolar area. The roots were partially separated near the apex, but mostly there are interradicular septa present along the lingual and buccal margins of the socket.

Table S1. Antemortem versus postmortem loss of the Cro-Magnon 4253 (Cro-Magnon 1) teeth. ${ }^{1,2}$.

\begin{tabular}{lllll}
\hline & Maxilla Right & Maxilla Left & Mandible Right & Mandible Left \\
\hline I1 & PM & PM & PM & PM \\
I2 & PM & PM & (AM/PM) & PM \\
C & PM & PM & PM & PM \\
P3 & PM & PM & Root & PM \\
P4 & PM & PM & PM & (PM) \\
M1 & PM & PM & Partial root & (AM/PM) \\
M2 & Partial tooth & (PM) & PM & PM \\
M3 & PM & PM & Partial root & PM \\
\hline
\end{tabular}

${ }^{1} \mathrm{PM}$ indicates probable antemortem or postmortem tooth loss respectively. AM/PM indicates uncertainty

${ }^{2}$ Parentheses around "AM" or "PM" indicates uncertainty in the assessment. 


\section{S3: Cro-Magnon 4254 (Cro-Magnon 2) Maxillary Dentoalveolar Remains}

The Cro-Magnon 4254 maxillary alveoli, part of the Cro-Magnon 2 cranium, are largely preserved from the right mesiolingual $\mathrm{M}^{3}$ socket around anteriorly to the left mesial $\mathrm{M}^{2}$ alveolus (Fig. S6). The labial surfaces are absent from the right $\mathrm{I}^{1}$ to the left $\mathrm{I}^{2}$, and there is breakage to the buccal right $\mathrm{P}^{3}$ and $\mathrm{P}^{4}$ alveoli. The bone is otherwise well preserved, clean of matrix, and retains most of its alveolar crest. There are two largely complete right molars and a root fragment in situ in the left $\mathrm{M}^{1}$ alveolus.

All of the alveoli either preserve teeth or tooth fragments or are clean and open with normal lamina dura. There is no evidence of antemortem tooth loss. Most of the left $\mathrm{M}^{1}$ alveolus and all of the left $\mathrm{M}^{3}$ alveolus and adjacent maxilla are absent, providing little or no data on those teeth. The only non-dental anomaly is a wide $(3.6 \mathrm{~mm})$ diastema between the $\mathrm{I}^{1} \mathrm{~s}$.

\section{$I^{1}$ Right}

The lingual half of the alveolus with the intact lingual alveolar margin is present. There is no resorption or other alterations, except for a slight rounding of alveolar crests. There is a separation of $3.6 \mathrm{~mm}$ between the $\mathrm{I}^{1}$ alveoli and across the intermaxillary suture.

$I^{1}$ Left

The lingual half of the alveolus is present with the intact lingual and mesial alveolar margins. There is no resorption or other alterations, except for a slight rounding of alveolar crests.

$I^{2}$ Right

The alveolus is complete except for a slight loss of the thin bone on the labial margin of the socket. There is a slight irregularity of the mesial and distal interdental alveolar crests.
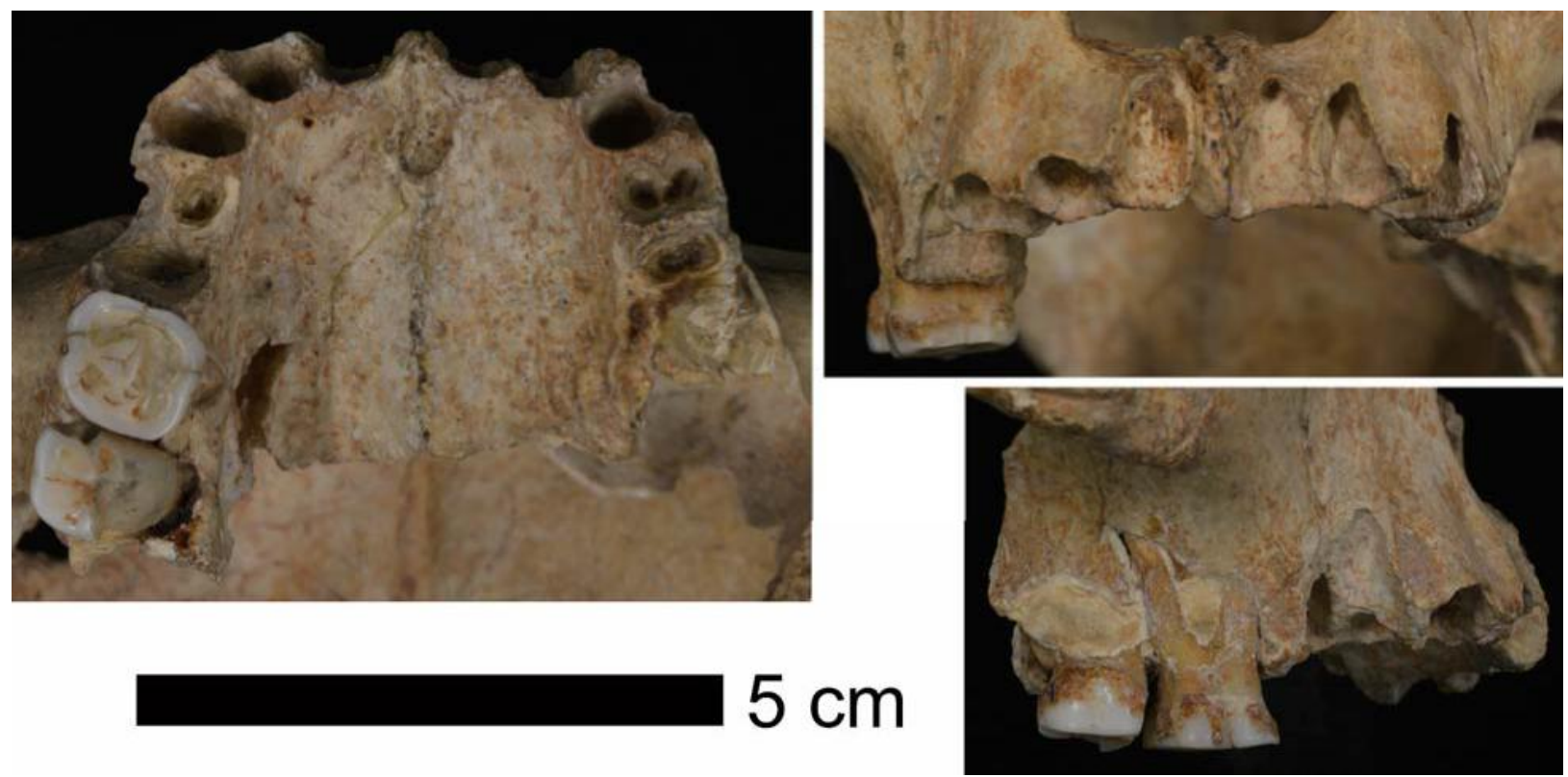

Figure S6. The Cro-Magnon 4254 (Cro-Magnon 2) maxillae in occlusal (left), anterior (upper right) and right lateral (lower right) views. 
319 The lingual and distal sides of the socket are preserved, with breakage to the mesial and

\section{$C^{l}$ Right}

The alveolus presents a large ovoid socket, that extends $15-16 \mathrm{~mm}$ up into maxilla, with the apex curving distally at the top over the $\mathrm{P}^{3}$ socket (see right $\mathrm{P}^{3}$ ). The alveolar crest is intact, if slightly rising on the labial side.

$C^{1}$ Left

The large ovoid socket is similar to the right one, but with the labial side broken. The socket is shorter than the right one (14.4 $\mathrm{mm}$ from the $\mathrm{C}^{1} / \mathrm{P}^{3}$ septum); it is straight and conical, with none of the apical distal curving evident on the right.

$P^{3}$ Right

The $\mathrm{P}^{3}$ alveolus is broken away buccally and abraded lingually, but it is otherwise intact. There is a small socket lingually, with its maximum diameter of $5.0 \mathrm{~mm}$ oriented obliquely to the tooth row, up against the distolingual $\mathrm{C}^{1}$ socket. The long axis is mesiolingual to distobuccal. The maximum depth of 5-6 mm may have been constrained by the $\mathrm{C}^{1}$ root curving above it.

The buccal root was longer but thinner, with its socket extending $12.5 \mathrm{~mm}$ from the alveolar crest. It is slightly obliquely oriented, more mesial occlusally and more distal above. The buccal side of the buccal alveolus would have protruded buccally relative to the external sides of the $\mathrm{C}^{1}$ and $\mathrm{P}^{4}$ alveoli.

The $\mathrm{P}^{3}$ was probably a two rooted tooth (as was the left $\mathrm{P}^{3}$ ), but with markedly asymmetrical buccal and lingual root, the latter being much smaller in diameter and length than the former.

$P^{3}$ Left

The alveolus exhibits a broad rectangular socket with rounded buccal and lingual margins. The $\mathrm{P}^{3}$ had a clear double root, although the septum is incomplete on the mesial side and largely absent on the distal side until $\approx 7 \mathrm{~mm}$ down from the $\mathrm{C}^{1} / \mathrm{P}^{3}$ septum. There is a little rounding of the alveolar margins, with a slight retraction of the alveolar crest on the lingual side and the buccal margins.

$P^{4}$ Right

The alveolus presents a normal $\mathrm{P}^{4}$ single rooted socket, tapering to a rounded apex. It was broken buccally and mesiobuccally, but intact lingually and distally.

$P^{4}$ Left

There is a normal single rooted $\mathrm{P}^{4}$ socket, which is relatively shallow $(7.9 \mathrm{~mm}$ versus $10.5 \mathrm{~mm}$ for the right $\mathrm{P}^{4}$ ). There is a small but distinct midline ridge on distal side of the socket, indicating a longitudinal sulcus on the root, but no bifurcation. The distal half of the alveolar crest is a thin and rounded margin. 
The right $\mathrm{M}^{1}$ presents a complete tooth (despite normal occlusal wear) in situ. The lingual root is exposed near the cervix due to postmortem bone loss, and the buccal roots are almost completely exposed buccally due to postmortem surface bone loss. The tooth is moderately worn (Smith (1984) stage 5a). There are the remains of extensive calculus on the crown and cervix.

\section{$M^{1}$ Left}

The preserved alveolus consists primarily of the mesial and lingual margins with small portions of the adjacent root sockets. The buccal alveolus is broken, and the buccal two-thirds of the area is plastic filler. The lingual alveolar margin is greatly reduced and descends at the level of the $\mathrm{M}^{1} / \mathrm{M}^{2}$ septum almost to the palate. The edge is rounded and irregular, and has a small foramen at its mesial $\left(\mathrm{P}^{4} / \mathrm{M}^{1}\right)$ end. Within the area of the socket, along the inside of the raised lingual edge, there is the $\approx 4.3 \mathrm{~mm}$ long apical end of the lingual root.

Therefore, the left $\mathrm{M}^{1}$ left appears to have experienced serious alveolar resorption, especially lingually, that began mesially in the mid- $\mathrm{P}^{4}$ socket and continued through the $\mathrm{M}^{1}$ to reach close to the level of the $\mathrm{M}^{1}$ lingual root apex and the palate. Hence the left $\mathrm{M}^{1}$ was in place at death, but its roots were extensively exposed, especially lingually.

Table S2. Dental mesiodistal (MD) and buccolingual (BL) crown diameters of the sufficiently intact Cro-Magnon teeth compared to those of Early/Mid (E/MUP) and Late (LUP) Upper Paleolithic samples [mean \pm standard deviation $(\mathrm{N})$ ], in millimeters.

\begin{tabular}{lcccccl}
\hline & 4254 & 4257 & 4258 & E/MUP & LUP & $\mathrm{p}^{1}$ \\
\hline $\mathrm{P}^{4} \mathrm{MD}$ & & 7.9 & & $7.1 \pm 0.5(21)$ & $6.5 \pm 0.7(10)$ & $0.008^{*}$ \\
$\mathrm{P}^{4} \mathrm{BL}$ & & 11.2 & & $9.9 \pm 0.6(31)$ & $9.6 \pm 0.6(16)$ & 0.079 \\
$\mathrm{M}^{1} \mathrm{MD}$ & $(11.0)$ & $(13.0)$ & & $10.8 \pm 0.7(46)$ & $10.5 \pm 0.9(17)$ & 0.206 \\
$\mathrm{M}^{1} \mathrm{BL}$ & 12.4 & 14.1 & & $12.2 \pm 0.8(49)$ & $11.8 \pm 1.0(33)$ & 0.027 \\
$\mathrm{M}^{2} \mathrm{MD}$ & $(9.5)$ & $(11.6)$ & & $10.3 \pm 0.9(39)$ & $10.0 \pm 0.8(14)$ & 0.190 \\
$\mathrm{M}^{2} \mathrm{BL}$ & $(12.5)$ & 13.9 & & $12.4 \pm 0.9(43)$ & $11.9 \pm 1.1(31)$ & 0.038 \\
$\mathrm{M}_{2} \mathrm{MD}$ & & & $(13.0)^{2}$ & $11.4 \pm 0.8(44)$ & $11.0 \pm 0.8(12)$ & 0.166 \\
$\mathrm{M}_{2} \mathrm{BL}$ & & & $(12.5)^{2}$ & $11.0 \pm 0.7(51)$ & $10.8 \pm 0.7(36)$ & 0.182 \\
$\mathrm{M}_{3} \mathrm{MD}$ & & & $(11.9)$ & $11.4 \pm 1.0(20)$ & $10.7 \pm 0.7(11)$ & 0.052 \\
\hline
\end{tabular}

${ }^{1}$ ANOVA p-values across the two comparative samples. *: Only the $\mathrm{P}^{4} \mathrm{MD}$ diameters are significantly different at $\mathrm{p}<0.05$ with a multiple comparison correction.

${ }^{2}$ The $\mathrm{CM} 4258 \mathrm{M}_{2}$ diameters are the estimated values. The actual values are $\geq 12.5$ and $\geq 12.0 \mathrm{~mm}$ respectively (see text below).

\section{$M^{2}$ Right}

The right $\mathrm{M}^{2}$ alveolus retains the complete lingual side, rounding into the $\mathrm{M}^{1} / \mathrm{M}^{2}$ septum mesially and the $\mathrm{M}^{2} / \mathrm{M}^{3}$ septum distally. The buccal and distal alveolus is absent and partially filled with plaster. The tooth is largely in place, but with a $1.8 \mathrm{~mm}$ gap with sediment lingually. The roots and dentin core are largely complete, but the enamel lacks the lingual half and the mesial margin. The tooth shows little wear (Smith stage $3 b$ ). There is half of a small distal interproximal wear facet preserved.

The current gap between lingual alveolus and the $\mathrm{M}^{2}$ was filled with wax in the 1970s, and the wax had been removed by the 1980s, following photos by ET taken in 1978 and 1985. It 
is therefore likely that the tooth was observed and measured in the 1960s by Vallois and Billy (1965) with the wax in place. The lingual half of the crown enamel was absent at both times, and sediment traces on the exposed dentoenamel surface suggests that the enamel was lost prior to 1868 . The $\mathrm{M}^{2}$ crown diameters of Vallois and Billy (1965), of 12 and $9 \mathrm{~mm}$, are therefore of the reduced tooth; estimation of the missing enamel provides mesiodistal and buccolingual crown diameters of $\approx 9.5$ and $\approx 12.5 \mathrm{~mm}$ respectively. The tooth also exhibits extensive calculus on the crown.

\section{$M^{2}$ Left}

The only evidence for the left $\mathrm{M}^{2}$ is an edge of its lingual alveolus $7.7 \mathrm{~mm}$ long, that continues the resorbed edge of the $\mathrm{M}^{1}$ alveolus. It is only slightly above the level of the palate and reaches the palatal level distally. There is a hint of the mesial end of its lingual root socket apex.

$M^{3}$ Right

There is a small area of mesiolingual lamina dura, $3.8 \mathrm{~mm}$ wide and $7.8 \mathrm{~mm}$ high, distal of the $\mathrm{M}^{2}$ socket, for the $\mathrm{M}^{3}$. In combination with the distal interproximal facet on the $\mathrm{M}^{2}$, it indicates that the $\mathrm{M}^{3}$ was in occlusion normally.

\section{S4: Cro-Magnon 4256 Mandibular Dentoalveolar Remains}

The Cro-Magnon 4256 mandibular corpus retains most of the alveoli of all sixteen mandibular teeth, from the distal right $\mathrm{M}_{3}$ alveolus to the distal portion of the left $\mathrm{M}_{3}$ alveolus. There is variable fossilization damage/abrasion, especially buccally, but most of the interdental septa are intact. Thirteen of the sockets are empty without resorption indicating postmortem tooth loss. The other three alveoli, those for the left $\mathrm{I}_{1}$ and both $\mathrm{P}_{3}$ sockets, hold broken roots in situ. There is also obscuring matrix in the left $\mathrm{I}_{1}, \mathrm{I}_{2}$ and $\mathrm{P}_{3}$ sockets.

The alveoli, however, present a suite of anomalies of dental orientation. The $\mathrm{I}_{2} \mathrm{~S}$ are rotated mesiolabially, the $\mathrm{P}_{3}$ s are rotated mesiolingually, the $\mathrm{M}_{2}$ s slope mesially, and the right $\mathrm{M}_{3}$ exhibits an unusual root pattern (Fig. S7; Table S3).

\section{I1 Right}

The alveolus retains a normal mesiodistally narrow socket with loss of the superior half of the labial alveolar bone.

\section{Il Left}

The left $\mathrm{I}_{1}$ root is still in situ, and it is a very mesiodistally thin normal root. Distal of the root in the socket there is matrix, in some space between the root and the $\mathrm{I}_{1} / \mathrm{I}_{2}$ septum.

\section{I2 Right}

The $\mathrm{I}_{2}$ socket is normal in form with loss of the superior third of the labial bone. The tooth was set largely parallel to the $\mathrm{I}_{1}$, albeit with the labial side closer to the $\mathrm{I}_{1}$. The tooth therefore exhibits mild mesiolabial rotation, also present in the left $\mathrm{I}_{2}$. As a result, the $\mathrm{I}_{2} / \mathrm{C}_{1}$ septum is triangular, with a broader labial portion, given that the labiolingual axis of the $\mathrm{C}_{1}$ is perpendicular to the curve of the dental arcade. 
Despite matrix and damage to the $\mathrm{I}_{2} / \mathrm{C}_{1}$ septum, the left $\mathrm{I}_{2}$ parallels the right one, in anteroposterior orientation and a resultant triangular $\mathrm{I}_{2} / \mathrm{C}_{1}$ septum that is labially thick. With the $\mathrm{I}_{1} \mathrm{~s}$, the two rotated $\mathrm{I}_{2} \mathrm{~s}$ would have provided a transverse line of labial incisors, but with labial gaps $\mathrm{I}_{2}$ to $\mathrm{C}_{1}$.

\section{$C_{1}$ Right}

It exhibits a broad and straight socket, with labial bone loss on the superior half of the socket, and a small lip of bone along its lingual side.

\section{$C_{1}$ Left}

The left $\mathrm{C}_{1}$ socket is similar to the right one, although less expanded mesiodistally on its labial side.
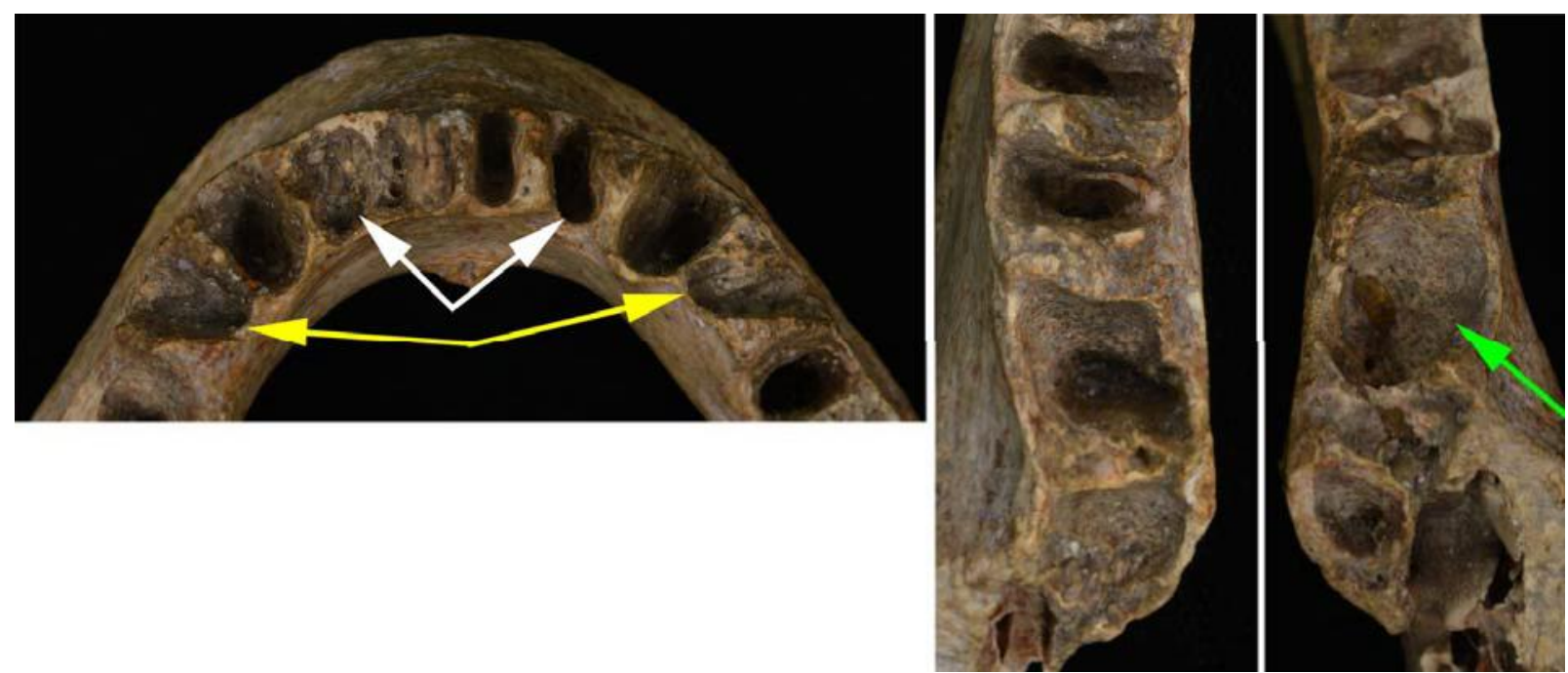

Figure S7. Details of the Cro-Magnon 4256 alveoli; from left to right: anterior alveoli, right molar alveoli, left molar alveoli. White arrows: rotated $\mathrm{I}_{2} \mathrm{~s}$. Yellow arrows: rotated $\mathrm{P}_{3} \mathrm{~s}$. Green arrow: mesially sloping $\mathrm{M}_{2}$.

\section{$P_{3}$ Right}

The $\mathrm{P}_{3}$ socket retains a mesiodistally thin root. There is some buccal alveolar resorption. The tooth was rotated $\approx 60^{\circ}$, lingual to mesial/buccal to distal. The rotation produced a very thin lingually but $5.0 \mathrm{~mm}$ thick buccally. $\mathrm{C}_{1} / \mathrm{P}_{3}$ septum. The $\mathrm{P}_{3} / \mathrm{P}_{4}$ septum is $2.7 \mathrm{~mm}$ buccally and 4.5 $\mathrm{mm}$ thick lingually. 
The alveolus exhibits a normal thicker root socket, oriented correctly. There is minor reduction of the $\mathrm{P}_{4} / \mathrm{M}_{1}$ alveolar crest.

\section{$P_{4}$ Left}

Table S3. The distribution of rotated incisors, canines and premolars in the Cro-Magnon sample. ${ }^{1}$

\begin{tabular}{|c|c|c|c|c|c|}
\hline & I1 & I2 & $\mathrm{C}$ & P3 & P4 \\
\hline \multicolumn{6}{|l|}{ CM 4253} \\
\hline Maxilla right & abs & abs & abs & abs & abs \\
\hline Maxilla left & abs & abs & abs & (pres) & abs \\
\hline Mandible right & abs & abs & (pres) & pres & abs \\
\hline Mandible left & abs & abs & abs & abs & abs \\
\hline \multicolumn{6}{|l|}{ CM 4254} \\
\hline Maxilla right & abs & abs & abs & abs & abs \\
\hline Maxilla left & abs & abs & abs & abs & abs \\
\hline \multicolumn{6}{|l|}{ CM 4256} \\
\hline Mandible right & abs & pres & abs & pres & abs \\
\hline Mandible left & abs & pres & abs & pres & abs \\
\hline \multicolumn{6}{|l|}{ CM 4257} \\
\hline Maxilla left & abs & abs & abs & pres & abs \\
\hline
\end{tabular}
some resorption on the distal side.

The socket is similar the right $\mathrm{P}_{4}$ one, with the normal lamina dura on the mesial side and

${ }^{1}$ (pres) for two of the CM 4253 teeth indicates possible rotation, with uncertainty given resorption and/or damage to the alveoli.

\section{Ml Right}

The $\mathrm{M}_{1}$ alveolus presents two distinctly separated sockets, with damage to the broad interradicular septum. There is some alveolar resorption along the lingual margin, but it is broken buccally.

\section{Ml Left}

The alveolus has normal paired root sockets, well separated by a high (especially buccally) and thick interradicular septum. There was moderate alveolar resorption lingually, and damage to the buccal margin of the mesial root.

\section{M2 Right}

The $\mathrm{M}_{2}$ socket presents a single "conical" socket for fused roots, with thin and small crests lingually and buccally for the sulci between the fused roots. However, the hole slopes mesially, such that the distal lamina dura is vertical to the alveolar plane and the mesial one is at a distinct angle to the alveolar plane. There is also a pronounced thickness $(4.8 \mathrm{~mm})$ of the 
$\mathrm{M}_{1} / \mathrm{M}_{2}$ septum. This combination of features suggests that the $\mathrm{M}_{2}$ was erupted to the occlusal plane, but that its crown was angled up against the $\mathrm{M}_{1}$. It therefore had the root angled distally,

\section{S5: Cro-Magnon 4257 Maxillary Dentoalveolar Remains}

The $\mathrm{M}_{2}$ socket is partly obscured by thin matrix, but it is similar to the right one; a conical socket for fused roots, a vertical distal septum, an angled mesial septum, and a thickened $\mathrm{M}_{1} / \mathrm{M}_{2}$ septum. However, the mesial angle is less pronounced, and the thickness of the septum $(3.4 \mathrm{~mm})$ is less.

\section{M3 Right}

The root socket pattern for the right $\mathrm{M}_{3}$ is unusual, although the breakage of the distobuccal alveolus makes its full aspect unclear. There is a mesial midline narrow root $(6.5$ $\mathrm{mm}$ wide versus $8.4 \mathrm{~mm}$ for the $\mathrm{M}_{2}$ socket) socket which then tapers to a narrowing $5.4 \mathrm{~mm}$ from the alveolar plane. To the distal on the lingual side, there is an oval socket 4.5 by $3.5 \mathrm{~mm}$, largely vertically oriented, and $\approx 4 \mathrm{~mm}$ deep. The mesial socket should be for a reduced mesial $\mathrm{M}_{3}$ root, but it is unclear whether the distolingual socket is for a reduced and rotated distal root.

\section{M3 Left}

Only the mesial lamina dura is preserved. It is flat and a normal $\mathrm{M}_{3}$ mesial root surface, but it slopes slightly mesially, similar to the $\mathrm{M}_{2}$ mesial root surface.

CM 4257 is a complete alveolar and palatal portion of a left maxilla, with the alveoli from the intermaxillary suture mesial of $\mathrm{I}^{1}$ to the alveolar bone around the missing $\mathrm{M}^{3}$ (Fig. S8). The maxillary portion of the palate is complete, but the labial/buccal portions of the alveoli from $\mathrm{I}^{1}$ to $\mathrm{P}^{4}$ are largely or entirely absent.

The maxilla currently retains the $\mathrm{M}^{1}, \mathrm{M}^{2}$ and a $\mathrm{P}^{4}$. The conditions of the preserved sockets all indicate portmortem loss of the absent teeth.

In addition, the largely complete $\mathrm{P}^{4}$, which has been in the maxilla since the initial description of Broca (1868), does not belong in the maxilla (see below). It is not clear whether it derives from the same individual but is a right $\mathrm{P}^{4}$ or it comes from another individual. Its buccolingual crown diameter is unexceptional relative to those of the $\mathrm{M}^{1}$ or especially of the $\mathrm{M}^{2}$, and its degree of occlusal wear matches that of the $\mathrm{M}^{2}$, both of which should have the same functional occlusal age. It is therefore conservatively considered to be the right $\mathrm{P}^{4}$ of CroMagnon 4257.

\section{$I^{l}$ Left}

Present is the complete lingual third to half of the socket with the intact lamina dura. There is matrix in its apical portion.

$I^{2}$ Left

Present is the complete lingual third of the socket with the intact lamina dura. 


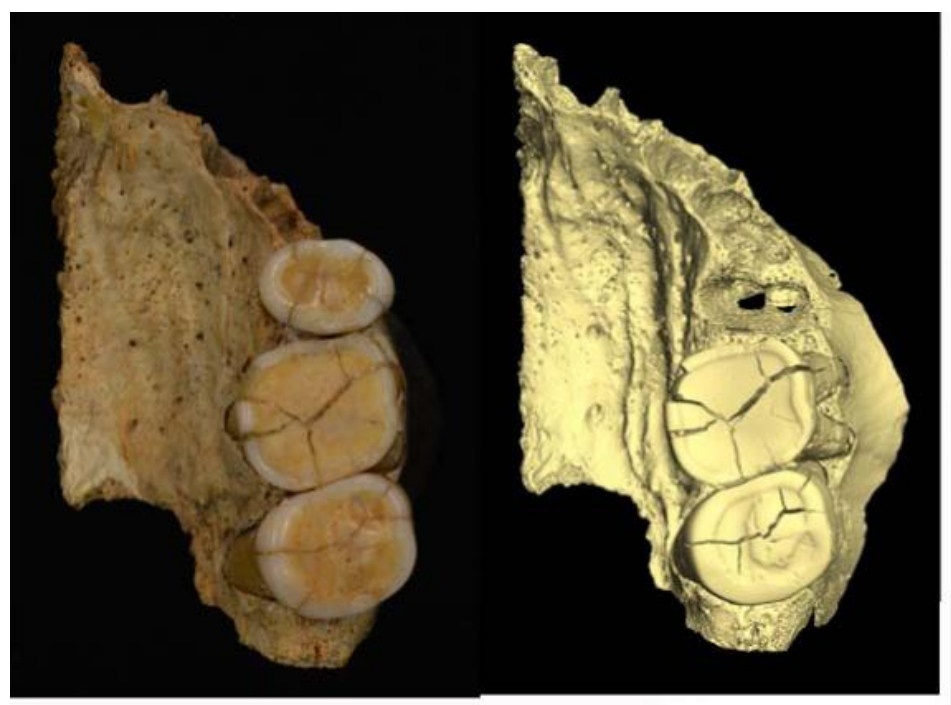
labially. There is minor porosity of the lamina dura along the $\mathrm{I}^{2} / \mathrm{C}^{1}$ septum.

Preserved is the complete lingual half of the socket with the apical portion partly covered

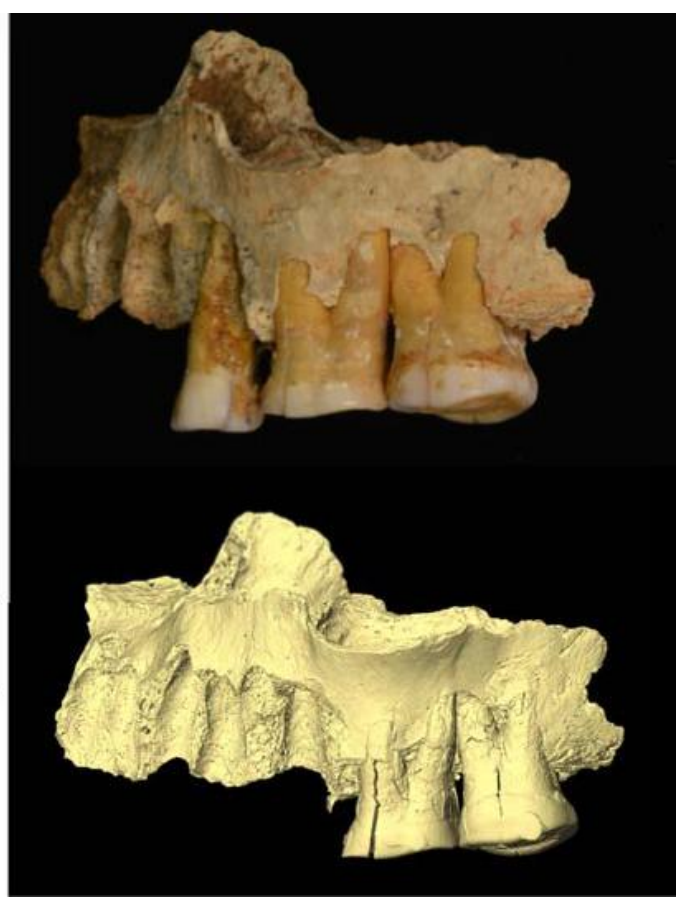

Figure S8. Occlusal (left) and buccal (right) views of the Cro-Magnon 4257 left maxilla. Shown are photographs of the maxilla with the $\mathrm{P}^{4}$ in its current position and virtual images of the maxilla with the $\mathrm{P}^{4}$ removed. Note the slightly more anterolateral than lateral view of the virtual image.

$P^{3}$ Left

The left $\mathrm{P}^{3}$ alveolus retains its mesial, lingual and distal portions, and presents two sockets with a septum that extends almost to the alveolar margin. As noted by Vallois and Billy (1965), it is best interpreted as a two-rooted $\mathrm{P}^{3}$. It is also rotated almost $90^{\circ}$ in the alveolus.

$P^{4}$ Right

As noted above, the complete $\mathrm{P}^{4}$ currently in the left $\mathrm{P}^{4}$ alveolus was inappropriately placed in that socket, apparently shortly after its discovery. Although the tooth is morphologically a $\mathrm{P}^{4}$, with a single root and with buccal and lingual cusps of similar size (the buccal one is slightly larger), it does not fit the CM 4257 left maxilla. Its root is completely pressed into the left $\mathrm{P}^{4}$ alveolus, but its occlusal surface projects $2.2 \mathrm{~mm}$ above that of the $\mathrm{M}^{1}$. The very small interproximal facet of the $\mathrm{P}^{4}$ does not match the large one on the mesial $\mathrm{M}^{1}$, and the $\mathrm{P}^{4}$ one is above that of $\mathrm{M}^{1}$. The contour of the distal $\mathrm{P}^{4}$ crown does not match that of the $\mathrm{M}^{1}$, unlike the close fitting of the interproximal facets between the $\mathrm{M}^{1}$ and the $\mathrm{M}^{2}$.

Yet, as noted above, the degree of wear of the $\mathrm{P}^{4}$ (Smith stage $5 \mathrm{~b}$ ) is similar to that of the $\mathrm{M}^{2}$ (Smith stage 5c). Also, comparisons of the $\mathrm{P}^{4}$ versus $\mathrm{M}^{1}$ and $\mathrm{M}^{2}$ buccal crown diameters are unexceptional for Late Pleistocene human (Fig. S9). The tooth cannot be easily sided, given the 
symmetry of the crown and its straight root, but it would make an appropriate right $\mathrm{P}^{4}$ of the same individual. It is so considered.

The right $\mathrm{P}^{4}$ tooth therefore present an ovoid crown with the remains (after wear) of the mesial and distal marginal ridges and an absence of a develomental groove. It has a single straight root.
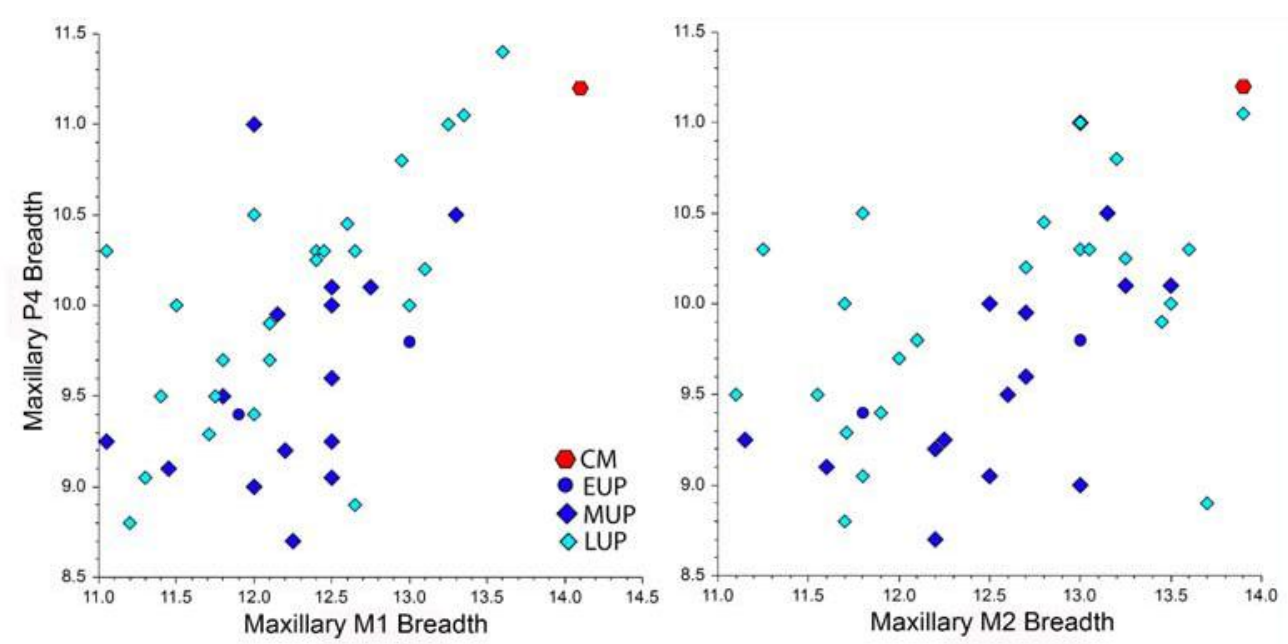

Figure S9. The buccolingual diameter of the Cro-Magnon $4257 \mathrm{P}^{4}$ (in mm) compared to the same diameter for its $\mathrm{M}^{1}$ (left) and $\mathrm{M}^{2}$ (right) (Table $\mathrm{S} 2$ ), versus the same comparisons for Early (EUP), Mid (MUP) and Late (LUP) Upper Paleolithic humans.

$P^{4}$ Left

The left $\mathrm{P}^{4}$ alveolus, with the right one removed virtually (Fig. S8), presents a normal socket for a single rooted premolar, with small ridges (especially mesially) for the sulci running along the root.

$M^{1}$ Left

The in situ $\mathrm{M}^{1}$ is a complete tooth and alveolus with the loss of thin alveolar bone on the buccal and lingual sides, exposing much of the roots. The occlusal surface is a dentin basin with a continuous ring of enamel around it (Smith stage 7b); the loss on the mesiolingual corner is postmortem breakage. There are postmortem fissures through the crown, with little of the crown dimensions; any expansion of the mesiodistal diameter (the only one likely to be affected) is more than compensated by the interproximal wear (it measures $12.8 \mathrm{~mm}$, rounded off to $\approx 13.0$ $\mathrm{mm})$.

\section{$M^{2}$ Left}

The $\mathrm{M}^{2}$ is a complete tooth in situ with lingual and especially buccal exposures of most of the roots. It has a tight and congruent mesial interproximal flat contact facet with the $\mathrm{M}^{1}$, but there is no distal interproximal facet. The occlusal surface exhibits a rounded enamel ring, a dentin basin with a center enamel island connected to the enamel ring only on the mid-buccal side (Smith stage 5c). The tip of the mesiolingual root is exposed through breakage alongside of the $\mathrm{M}^{3}$ crypt (see below); although slightly damaged, the apex of the root was fully closed. 


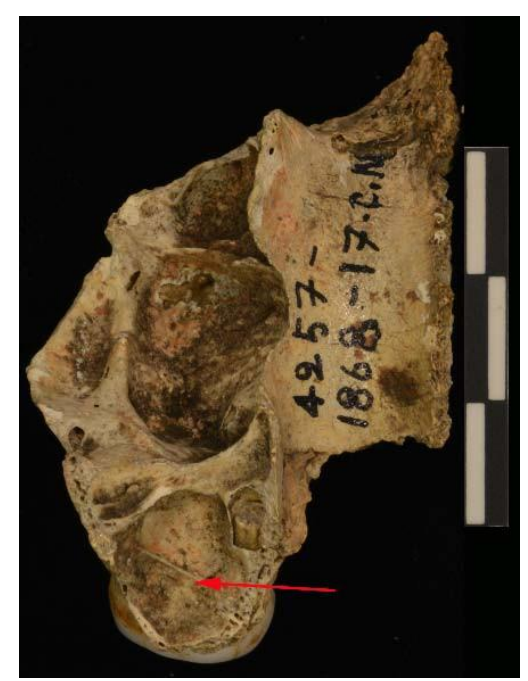

Figure S10. The Cro-Magnon 4257 maxilla in superior view. Note the crypt for the impacted $\mathrm{M}^{3}$ (red arrow) above the erupted and worn $\mathrm{M}^{2}$.

\section{$M^{3}$ Left}

The $\mathrm{M}^{3}$ is absent and the retromolar bone extends for only $6.9 \mathrm{~mm}$ distal of the $\mathrm{M}^{2}$ cervix. Superior of the retromolar bone is a crypt $12.2 \mathrm{~mm}$ mesiodistal and $8.9 \mathrm{~mm}$ buccolingual for the crown of the $\mathrm{M}^{3}$ (Fig. S10). Because the $\mathrm{M}^{2}$ and especially the $\mathrm{M}^{1}$ are heavily worn and the $\mathrm{M}^{2}$ roots are closed, this space does not represent a crypt for a developing $\mathrm{M}^{3}$. It reflects an impacted $\mathrm{M}^{3}$ crown up against the distal $\mathrm{M}^{2}$ root, as noted by Vallois and Billy (1965).

\section{S6: Cro-Magnon 4258 Mandibular Dentoalveolar Remains}

The Cro-Magnon 4258 mandibular piece consists of the alveolar region from the middle of the $\mathrm{M}_{1}$ to the ramus (Fig. S11). The alveolar bone is well preserved buccally, especially by the $M_{2}$ and $M_{3}$, but it is partially present by the $M_{1}$ and absent from the $M_{2}$ and the mesial $M_{3}$. All three of the teeth, the $M_{1}$ to $M_{3}$, are present. However, the $M_{1}$ lost most of its mesial and buccal enamel and the $\mathrm{M}_{2}$ lost most of its lingual and buccal enamel. The intact $\mathrm{M}_{3}$ is impacted with its mesial crown against the distal $\mathrm{M}_{2}$ root and the distal crown not quite at the alveolar plane.

The mandible is labeled "Cro-Magnon n ${ }^{\circ}$ ", possibly based on Pruner-Bey (1865-75), but it remains unclear to which of the crania it might have belonged.

Vallois and Billy (1965) mentioned four teeth associated with the CM 4258 mandible, $\mathrm{P}_{4}$ to $\mathrm{M}_{3}$. There is no current evidence of a premolar with CM 4258, and Pruner-Bey (1865-75) mentioned only the three currently present molars. It is not clear to what premolar Vallois and Billy were referring.

\section{Ml Right}

The $\mathrm{M}_{1}$ is a heavily worn tooth in situ, with a thin enamel around a dentin surface lingually, distally and on the distal half of the buccal side. The mesial half of the buccal crown and the buccal side of the mesial crown had the enamel worn away antemortem and the dentin rounding down below the cervix. As such it exhibits Smith wear stage 7c. Given damage to the alveolar bone, especially lingually, it is unclear to what extent it may have been resorbed (or the 
tooth supererupted), but the $\mathrm{M}_{1} / \mathrm{M}_{2}$ septum appears largely normal and the alveolar-cervix height $(\approx 2.5 \mathrm{~mm})$ is unexceptional for the degree of occlusal wear.

The mesiodistal diameter of the crown is too damaged and worn to measure. The
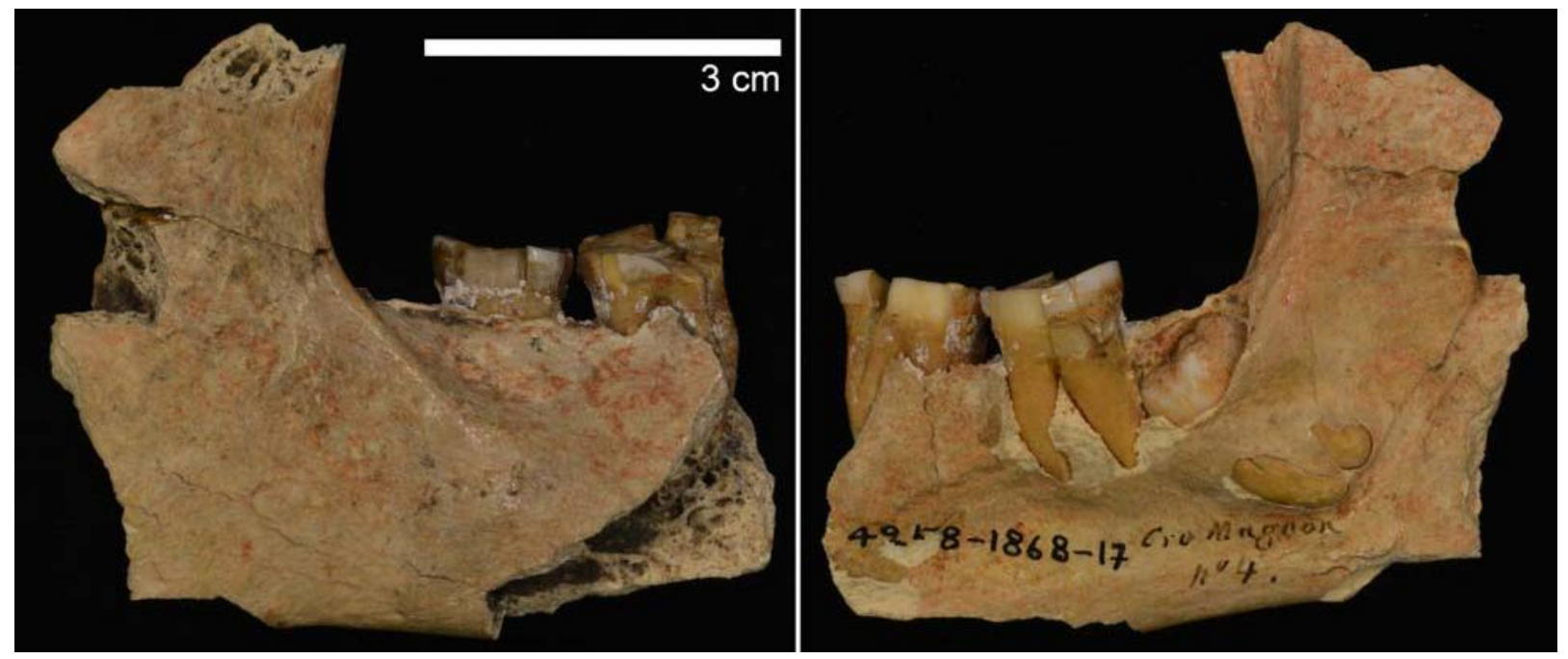

Figure S11. Lateral (left) and medial (right) views of the Cro-Magnon 4258 right mandibular corpus and ramus. See also text Fig. 4 and Fig. S12.

\section{$M_{2}$ Right}

The $\mathrm{M}_{2}$ exhibits a dentin occlusal surface with enamel margins preserved mesially and distally; it appears that the enamel ring was complete at death and the missing portions lost subsequently (Smith wear stage 7b). The lingual alveolar bone is absent, but the intact buccal alveolar bone exhibits no resorption. There is a small carious lesion occlusally, slightly lingually of the crown middle, noted by Brennan (1991) and Lacy (2014) (Fig. S12).

The mesiodistal diameter of the crown, as retained with occlusal and interproximal wear, is $12.5 \mathrm{~mm}$. The buccolingual diameter of the crown as worn, estimated continuing the contours of the broken enamel, is $\approx 12.0 \mathrm{~mm}$. Prior to the occlusal and interproximal wear, the two diameters were probably $\approx 13.0$ and $\approx 12.5 \mathrm{~mm}$. These values are approximate, but they provide a general assessment of the dimensions of these molar crowns.

\section{M3 Right}

As noted above, the completely formed $\mathrm{M}_{3}$ is fully present and fully impacted in the mandible. The mesial occlusal crown edge is against the $\mathrm{M}_{2}$ distal root slightly below the middle of the root. The long (vertical) axis of the tooth is $\approx 35^{\circ}$ from the alveolar plane. The buccal, distal and distolingual margins of the crypt opening through the alveolus are preserved, but little of the calculus on the distal $\mathrm{M}_{2}$ appears to have penetrated onto the $\mathrm{M}_{3}$ crown. 
697

698

699

700

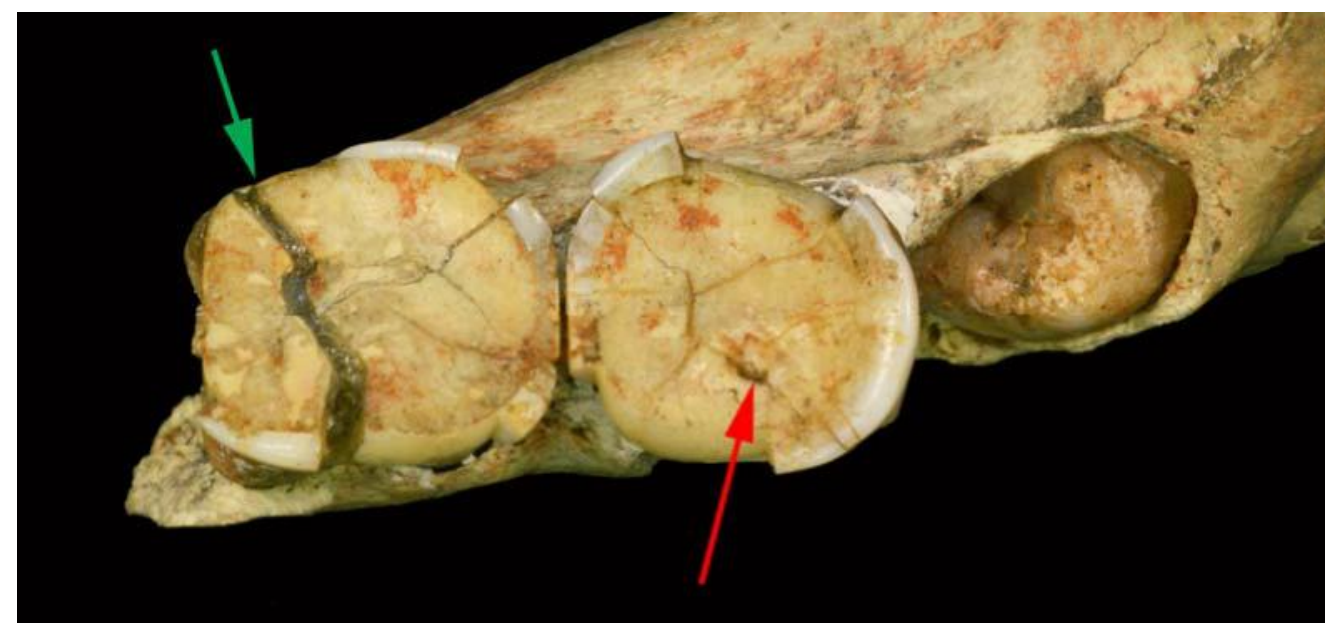

Figure S12. Occlusal views of the Cro-Magnon 4258 right mandibular molars, with the impacted $\mathrm{M}_{3}$ in its crypt. Green arrow: the rounded mesiobuccal edge of the $\mathrm{M}_{1}$. Red arrow: the small occlusal carious lesion in the $\mathrm{M}_{2}$.

\section{S7: Micro-CT Resolution Data}

Table S4. Resolutions of the microtomodensitometric $(\mu \mathrm{CT})$ data for the Cro-Magnon crania and mandibles.

\begin{tabular}{llr}
\hline CM 4253 Cranium & Cro-Magnon 1 & $115.0 \mu \mathrm{m}$ \\
CM 4253 Mandible & Cro-Magnon 1 & $76.6 \mu \mathrm{m}$ \\
CM 4254 Cranium & Cro-Magnon 2 & $110.0 \mu \mathrm{m}$ \\
CM 4256 Mandible & -- & $60.6 \mu \mathrm{m}$ \\
CM 4257 Maxilla & -- & $30.0 \mu \mathrm{m}$ \\
CM 4258 Mandible & -- & $38.2 \mu \mathrm{m}$ \\
\hline
\end{tabular}




\section{S8: Proposed Cro-Magnon Associations}

Table S5. Proposed associations of the Cro-Magnon adult remains, based on those proposed for the lower limbs by Thibeault and Villotte (2018), for the upper limbs by Villotte et al. (2020), and for the cranial and mandibular remains here. The individuals (Alpha to Delta) are those based on the appendicular remains, restricting the traditional Cro-Magnon 1 to 4 designations to the crania and the one directly associated mandible.

\begin{tabular}{lcccc}
\hline & Alpha & Beta & Gamma & Delta $^{2}$ \\
\hline Neurocranium & $4253(\# 1)$ & $4255(\# 3)$ or $4259(\# 4)^{1}$ & $4254(\# 2)$ \\
Maxilla/Mandible & $4253(\# 1)$ & 4256 or 4257/4258 & $4254(\# 2)$ \\
\hline Clavicle & 4290 & & & \\
Scapula & 4292 & 4294,4295 & 4293 & \\
Humerus & 4299 & 4301 & 4300,4302 & 4297,4298 \\
Ulna & 4304 & 4305 & 4303 & \\
Radius & $4314 \mathrm{a}, 4314 \mathrm{~b}$ & $4316 \mathrm{a}, 4317,4316 \mathrm{~b} ?$ & 4315,4318 \\
\hline Hip bone & $4314 \mathrm{c}$ & $4319 ?$ \\
Sacrum & $4323,4327,4325$ & $4321,4324,4329$ & $4322,4323,4328$ & \\
Femur & 4331,4332 & \multicolumn{4}{c}{4330,4333} \\
Tibia & 4335 & 4334 & \\
Fibula & & 4337 & \\
Talus & & 4336 & \\
Calcaneus & & & &
\end{tabular}

${ }^{1}$ As discussed in the text, the CM 4256 mandible and the CM 4257/4258 maxilla/mandible likely derive from the Beta and Gamma postcranial pair as well as from the CM 4255 and CM 4259 cranial pair. It is not currently possible to determine which way these three pairs might be associated.

${ }^{2}$ As discussed in the text, the association of CM 4254 cranium with Delta is largely based on its unlikely association with Beta or Gamma, and the assumption of only four adults in the Cro-Magnon sample.

\section{S9: Supporting Information References}

Brennan, M.U., 1991. Health and disease in the Middle and Upper Paleolithic of southwestern France: a bioarcheological study. Ph.D. Thesis. New York University.

Broca, P., 1868. Sur les crânes et ossements des Eyzies. Bull. Soc. Anthropol. Paris 3, 350-392. https://doi.org/10.3406/bmsap.1868.9548

Lacy, S.A., 2014. Oral Health and its Implications in Late Pleistocene Western Eurasian Humans. Ph.D.Thesis, Washington University in Saint Louis.

Leonard, A., Bayle, P., Murail, P., Brůžek, J., 2014. Oral exostoses: An assessment of two hundred years of research. Bull. Mém. Soc. Anthropol. Paris 26, 1-22. doi.10.1007/s13219-013-0089-3.

Pruner-Bey, F., 1865-75. An account of the human bones found in the cave of Cro-Magnon, in Dordogne, in: Lartet, E., Christy, H. (Eds.), Reliquiae Aquitanicae: Being Contributions 
to Archaeology and Palaeontology of Périgord and the Adjoining Provinces of Southern France. Williams and Norgate, London, pp. 73-92.

Smith, B.H., 1984. Patterns of molar wear in hunter-gatherers and agriculturalists. Am. J. Phys. Anthropol. 63, 39-56.

736

737

Vallois, H.V., Billy, G., 1965. Nouvelles recherches sur les hommes fossiles de l'abri de CroMagnon. L'Anthropol. 69, 47-74. 